\title{
Understanding Key Roles of Two ENSO Modes in Spatiotemporal Diversity of ENSO
}

\author{
RUN WANG \\ State Key Laboratory of Severe Weather, Chinese Academy of Meteorological Sciences, and University of Chinese Academy \\ of Sciences, and Laboratory for Climate Studies and China Meteorological Administration-Nanjing University Joint \\ Laboratory for Climate Prediction Studies, National Climate Center, China Meteorological Administration, Beijing, China
}

\section{HONG-Li REN}

State Key Laboratory of Severe Weather, Chinese Academy of Meteorological Sciences, and Laboratory for Climate Studies and China Meteorological Administration-Nanjing University Joint Laboratory for Climate Prediction Studies, National Climate Center, China Meteorological Administration, Beijing, and Department of Atmospheric Science, School of Environmental Studies, China University of Geoscience, Wuhan, China

(Manuscript received 14 October 2019, in final form 4 May 2020)

\begin{abstract}
El Niño-Southern Oscillation (ENSO) events exhibit a diversity of amplitudes, spatial patterns, and life cycles, with the main ENSO periods concentrated in the 3-7-yr [low-frequency (LF)] and 2-3-yr [quasibiennial (QB)] bands. In this study, the spatiotemporal diversity of ENSO is quantitatively examined by extracting the two ENSO modes, namely, the LF and QB components of ENSO, from the traditional Niño-3.4 index and connecting them with the spatial types of ENSO. El Niño events can be regrouped as the QBdominated central-Pacific ENSO-like (QB-CP), LF-dominated eastern-Pacific ENSO-like (LF-EP), and LFdominated mixing (LF-mixing) types. La Niña events with vague spatial patterns can also have the same categorization. The QB-CP and LF-EP El Niño types both have a high-amplitude QB component. Meanwhile, the former is less affected by its powerless LF component, but the latter is controlled by its strong LF component. Ocean dynamics of the two El Niño types are distinct from each other. The thermocline feedback dominates the growth of the two El Niño types and contributes to the phase transition of the LF-EP type, while the zonal advective feedback is of increasing importance in the QB-CP El Niño and mainly contributes to the phase transitions of the two El Niño types. Additionally, the LF-mixing type with ambiguous spatial features and complex life cycles is distinguished from the other two types. These results indicate that the two ENSO modes coexist in the tropical Pacific air-sea system, and their combination with changing amplitude is the key to explaining the spatiotemporal diversity of ENSO.
\end{abstract}

\section{Introduction}

El Niño-Southern Oscillation (ENSO) is a basin-scale phenomenon in the tropical Pacific that exerts a significant effect on global weather and climate. It is the most important interannual climate fluctuation on the time scale of 2-7 years. Since Bjerknes (1969) first recognized that positive air-sea coupled processes in the equatorial Pacific resulted in the development of ENSO, great progress has been made in recent decades in terms of understanding ENSO features and dynamics (Rasmusson and Carpenter 1982; Philander 1983; Battisti and Hirst 1989; Suarez and Schopf 1988; Cane et al. 1990; Jin 1996, 1997a,b; Picaut et al. 1997; Weisberg and Wang 1997;

Corresponding author: Prof. Hong-Li Ren, renhl@cma.gov.cn
Neelin et al. 1998; Wallace et al. 1998; An and Wang 2000; Wang and Picaut 2004; Chang et al. 2006). However, observed El Niño and La Niña events are known to vary in their spatiotemporal characteristics and correspond to different dynamic processes, climate impacts, and teleconnections (Fu et al. 1986; Trenberth et al. 1998; Kessler 2002; Larkin and Harrison 2002; Jin et al. 2003; An and Jin 2004; Yeh et al. 2009; Okumura and Deser 2010; Okumura et al. 2011; Giese and Ray 2011; Capotondi et al. 2015; Hu et al. 2017a; Timmermann et al. 2018).

Several studies in the past decade have focused on the spatial diversity of ENSO events (e.g., Chen et al. 2015; $\mathrm{Hu}$ and Fedorov 2018; Lemmon and Karnauskas 2019; Stevenson et al. 2019) and have primarily suggested separating El Niño events into two types based on the spatial patterns of sea surface temperature anomalies 
(SSTAs) (Larkin and Harrison 2005a,b; Ashok et al. 2007; Kao and Yu 2009; Kug et al. 2009; Yu and Kim 2010; Ren and Jin 2011, 2013): the canonical easternPacific (EP) El Niño events with the warmest SSTAs in the eastern equatorial Pacific and the so-called centralPacific (CP) El Niño events with the maximum SSTAs in the central equatorial Pacific (Kao and Yu 2009). Compared with El Niño, La Niña exhibits a smaller difference in spatial structure (Kug et al. 2009; Kug and Ham 2011; Ren and Jin 2011) and can be clearly separated into the two types after removing the background decadal variations (Ren et al. 2013). The two types of El Niño events have different properties, including amplitude, duration, spatial pattern, climate impact, and predictability (e.g., Weng et al. 2007; Zhang et al. 2011, 2012; Yeh et al. 2014; Ren et al. 2016, 2018, 2019a,b). The canonical EP El Niño events are accompanied by basinwide anomalous atmospheric circulations in the equatorial Pacific and a strong relaxation of the zonal equatorial thermocline tilt. In contrast, the CP El Niño events have anomalous variations mainly confined in the central equatorial Pacific with a weaker intensity (Kao and Yu 2009; Kug et al. 2009). Moreover, the primary positive dynamic feedbacks are different for the two types of $\mathrm{El}$ Niño events (Kug et al. 2009; Ren and Jin 2013). The thermocline feedback $(\mathrm{TH})$, which is connected with the recharge-discharge process of upper-ocean heat content, plays a dominant role in EP El Niño events, while the zonal advective feedback (ZA), which is mainly influenced by local atmospheric forcing, is crucial to the amplitude and phase transition of CP events (Kug et al. 2009). However, the contributions of the $\mathrm{TH}$ and $\mathrm{ZA}$ to the two types of $\mathrm{El}$ Niño remain controversial. Recent studies have suggested that the TH is also important for the development of $\mathrm{CP}$ events, which indicates that recharge/discharge processes are important for both types of El Niño events (Ren and Jin 2013; Xie et al. 2015).

Although the main periods of ENSO have a wide range of 2-7 years, previous studies have shown that ENSO periodicity can be mainly separated into a primary 3-7-yr [low-frequency (LF)] band and a secondary 2-3-yr [quasi-biennial (QB)] band (Rasmusson et al. 1990; Barnett 1991; Ropelewski et al. 1992; Jiang et al. 1995; An and Wang 2000; Kao and Yu 2009; Yeo et al. 2017). Accompanied by the identification of EP and CP ENSO events, studies have mentioned that the dominant period of the EP ENSO is associated with the LF band, while the CP ENSO is mainly exhibited in the QB band (Kao and Yu 2009; Ren and Jin 2013; Ren et al. 2013). Furthermore, around the year 2000, ENSO experienced an interdecadal regime change (Horii et al. 2012; McPhaden 2012; Hu et al. 2013, 2017b; Kumar and $\mathrm{Hu}$ 2014). The significant quasi-5-yr period of ENSO during 1980-99 became insignificant after 2000, while the quasi-2.5-yr variability of ENSO remained active (Xie et al. 2015; Wang and Ren 2017). Furthermore, there were three CP El Niño events (2002/03, 2004/05, 2009/10), one EP-CP mixed El Niño event (2006/07), and no typical EP El Niño events during 2000-10 (Yu and Kim 2013). Therefore, it may be inferred that there is a relationship between the two ENSO types and the two ENSO variability modes with the QB and LF periods (Ren et al. 2013; Wang and Ren 2017).

Studies have suggested that the QB and LF time scales are associated with two distinct modes (Rasmusson et al. 1990; Jiang et al. 1995; An and Wang 2000), namely, the QB and LF modes, which can describe the variations in ENSO swings in terms of their phases and amplitudes (White et al. 2003; Yeo and Kim 2014; Yeo et al. 2017). The interannual period of ENSO is closely related to the interdecadal change in the anomalous wind stress distribution in the tropical Pacific (An and Wang 2000). However, the spatiotemporal diversity of ENSO has not been clearly explained due to various limitations. Afterward, Bejarano and Jin (2008) theoretically obtained two leading ENSO-like coupled modes in a modified version of the Zebiak-Cane model (Zebiak and Cane 1987), the quasi-quadrennial (QQ) mode (corresponding to the LF mode) and the QB mode. The two independent modes coexist in the tropical Pacific and have different patterns and primary mechanisms (Bejarano and Jin 2008; Xie and Jin 2018). The zonal locations of their SSTA centers are mainly controlled by the relative strength of the TH and ZA. The LF mode exhibits its SSTA center in the eastern Pacific and is dominated by the $\mathrm{TH}$, while the QB mode is characterized by a westward-shifted SSTA center and is probably controlled by the ZA. The mentioned characteristics of the two ENSO modes closely resemble those of the typical EP and CP El Niño events, respectively, such as the 1997/98 EP El Niño event, which was similar to the QQ mode, and the 2009/10 CP El Niño event, which was similar to the QB mode (Timmermann et al. 2018). Hence, the two modes of ENSO can be used to interpret the two observed types of ENSO (Ren and Jin 2013; Ren et al. 2013; Wang and Ren 2017; Timmermann et al. 2018).

There is still less observational evidence to directly support the coexistence of the two physically independent ENSO-like modes and their correspondence to the two observed types of ENSO. Further questions are whether the simple one-to-one corresponding relationships between EP El Niño events and the LF mode and between CP El Niño events and the QB mode, are sufficient to explain both the spatial and temporal diversities of historical ENSO events. In this study, the QB and LF components of ENSO SSTAs represent the main focus, and the 
relationships between the two components and the characteristics of ENSO in terms of different types are identified to demonstrate the coexistence and manifestation of the two ENSO-like modes in observations. Through this study, we aim to emphasize that the combination of the two intrinsic ENSO modes is the key to explaining the observed spatiotemporal diversity of ENSO events. The remainder of this paper is organized as follows. The data and methods are introduced in section 2. The historic El Niño and La Niña events are regrouped according to their spatiotemporal characteristics in section 3 . We examine the spatiotemporal characteristics of the regrouped events and investigate the roles of the QB and LF modes in determining the spatiotemporal diversity of ENSO in section 4. A summary and a discussion are provided in section 5 .

\section{Data and methods}

\section{a. Data}

In this study, the monthly SST dataset is derived from the Extended Reconstructed Sea Surface Temperature version 5 (ERSSTv5; Huang et al. 2017) spanning from 1921-2018 with a horizontal resolution of $2^{\circ}$ latitude $\times$ $2^{\circ}$ longitude. The surface wind stress, ocean temperature and three-dimensional ocean current data are from the ensemble coupled data assimilation product (ECDA) of the Geophysical Fluid Dynamics Laboratory (GFDL; Zhang et al. 2007), spanning from 1961 to 2015. This dataset has 50 vertical levels (22 levels each with a thickness of $10 \mathrm{~m}$ in the top $220 \mathrm{~m}$ ) and a $1^{\circ} \times 1^{\circ}$ horizontal resolution with meridional spacing that gradually narrows to $1 / 3^{\circ}$ near the equator.

Due to interdecadal changes of the background state in the tropical Pacific (Hu et al. 2013; Xiang et al. 2013), a fixed climatic mean state would cause distortions in the spatial structures of ENSO, especially for the locations of the maximum (minimum) SSTAs in the equatorial Pacific at the peak time of El Niño (La Niña) events. In this study, referring to the standard definition of climate normals by the World Meteorological Organization (WMO) (WMO 1989, 2007; Arguez and Vose 2011), the monthly climatology is calculated by decadally sliding the 30-yr average, which is defined as follows:

$$
\begin{aligned}
\bar{x}(t, t+1, \ldots, t+9) & =\frac{1}{30} \sum_{i=t-10}^{t+19} x(i), \\
t & =1931,1941, \ldots, 1991 .
\end{aligned}
$$

Here, $t$ is a reference year, $x$ is the observed annual time series, and $\bar{x}$ is the climatology. The adjacent climatology is used for 1921-30 and 2001-18, respectively. Moreover, a 3-month running average is utilized here to remove high-frequency noises.
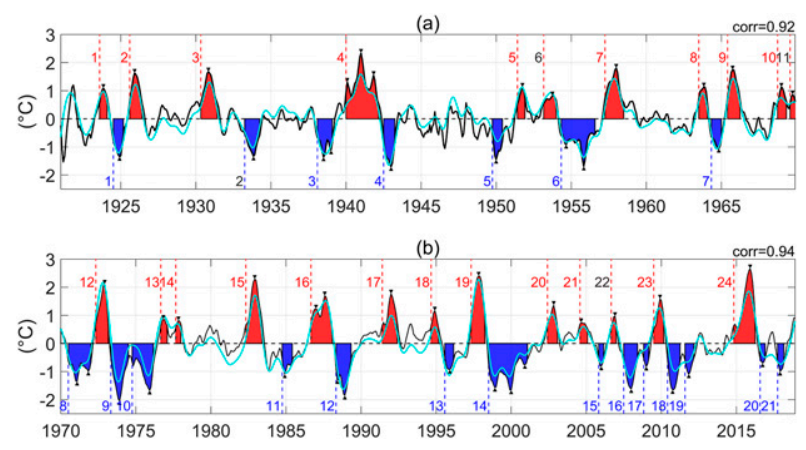

FIG. 1. (a),(b) Time series of the Niño-3.4 index (black line) and reconstructed by the QB and LF components (light blue line). The colored shading, black triangles, dashed lines, and numbers denote the durations, peaks, beginning times, and serial numbers of the El Niño or La Niña events, respectively. Red denotes El Niño, and blue denotes La Niña. The gray numbers correspond to the events that are excluded. The black numbers in the top right denote the correlation coefficients.

\section{b. Methods}

\section{1) IDENTIFICATION METHODS FOR EL NiÑO AND LA NIÑA EVENTS}

El Niño events are selected according to the criterion of the National Oceanic and Atmospheric Administration/ Climate Prediction Center (NOAA/CPC), in which the 3 -month running-average Niño-3.4 $\left(5^{\circ} \mathrm{N}-5^{\circ} \mathrm{S}, 170^{\circ}-120^{\circ} \mathrm{W}\right)$ index remains greater than or equal to $+0.5^{\circ} \mathrm{C}$ for at least 5 consecutive months. La Niña events are selected similarly but with the Niño-3.4 index remaining less than or equal to $-0.5^{\circ} \mathrm{C}$. This technique is consistent with Ren et al. (2018). We identified a total of $24 \mathrm{El} \mathrm{Niño} \mathrm{events}$ and 21 La Niña events during 1921-2018 (Fig. 1).

After identifying all the El Niño and La Niña events during 1921-2018, two ENSO features are defined: one is the peak time of the event, and the other is the zonal location of the equatorial Pacific SSTA center at the peak time. The peak time is defined as the time when the absolute value of the 3-month running-average Niño-3.4 index reaches its maximum in the $\mathrm{El}$ Niño or La Niña event, following Ren et al. (2018). Since ENSO is a basin-scale phenomenon, we need to select a stable and representative SSTA center at the mature stage of an event. Therefore, after using a zonal 15-point running mean $\left(30^{\circ}\right)$, a meridional mean over $5^{\circ} \mathrm{N}-5^{\circ} \mathrm{S}$, and a time average from 1 month before to 1 month after the peak time of El Niño and La Niña events, the zonal location of the SSTA center can be determined by the longitude of the maximum and minimum equatorial SSTA, respectively.

\section{2) ENSEMBLE EMPIRICAL MODE DECOMPOSITION}

To extract the QB and LF components from the equatorial Pacific SSTAs, the ensemble empirical mode 
decomposition (EEMD) method (Wu and Huang 2009) is employed in this study. The EEMD method is a data-adaptive filter for nonlinear and nonstationary time series data; this method is an extension of the traditional EMD method (Huang et al. 1998) and has been widely used in climate research (e.g., Qian et al. 2011). Using the (E)EMD method, a time series $x(t)$ can be decomposed into a finite number of oscillatory components called intrinsic mode functions (IMFs) with decreasing frequencies and a residual term $r(t)$, that is,

$$
x(t)=\sum_{i=1}^{n} \operatorname{IMF}_{i}(t)+r(t)
$$

where $n$ denotes the final number of IMFs.

The IMFs have two properties: 1) Over the whole temporal domain, the number of extrema and the number of zero-crossings must either be equal or differ at most by one. 2) At any point of data, the sum of the two envelopes defined by the local maxima and local minima is zero.

The EEMD method is an improvement over the traditional EMD method, as it can overcome the issue referred to as mode mixing, in which the EMD method often decomposes one intrinsic time scale into two or more IMFs. The procedure of the EEMD method is as follows:

1) Add a white noise series $w_{i}(t)$ to the original data $x(t)$ [Eq. (2)] and then apply the EMD to decompose the data into IMFs:

$$
x_{i}(t)=x(t)+w_{i}(t)
$$

2) Repeat step 1 many times but with different white noise series at each time.

3) Group the corresponding IMFs into ensembles and obtain the final result by averaging all ensembles of IMFs, which is called the IMF-like components.

\section{3) Heat Budget AnAlysis}

The heat budget of the oceanic mixed layer in the equatorial Pacific is calculated in this study using the linearized SST equation (An et al. 1999; Ren and Jin 2013; Lu et al. 2018):

$$
\begin{aligned}
\frac{\partial T^{\prime}}{\partial t}= & -\bar{u} \frac{\partial T^{\prime}}{\partial x}-\bar{v} \frac{\partial T^{\prime}}{\partial y}-\gamma \bar{w} \frac{T^{\prime}-T_{\mathrm{sub}}^{\prime}}{H_{m}} \\
& -u^{\prime} \frac{\partial \bar{T}}{\partial x}-v^{\prime} \frac{\partial \bar{T}}{\partial y}-w^{\prime} \frac{\partial \bar{T}}{\partial z}+Q,
\end{aligned}
$$

where $(T, u, v, w)$ denote the mixed layer ocean temperature and $3 \mathrm{D}$ ocean currents, respectively. Also, $T_{\text {sub }}^{\prime}$ is the subsurface temperature anomaly (averaged between 50 and $100 \mathrm{~m}, H_{\text {sub }}=75 \mathrm{~m}$ ), and $Q$ is the net anomalous heat flux at the sea surface. The overbar and prime notations denote the climatological mean and anomalies, respectively. For simplicity, the mixed layer depth $H_{m}$ is fixed at $50 \mathrm{~m}$. The parameter $\gamma=H_{m} / H_{\text {sub }}$ measures the effectiveness of the vertical entrainment (Zebiak and Cane 1987).

Following Jin et al. (2006) and Ren and Jin (2013), the right-hand side of Eq. (4) can be regrouped into the five linear feedback terms: the thermocline feedback term $\left[\mathrm{TH} ; \gamma \bar{w}\left(T_{\text {sub }}^{\prime} / H_{m}\right)\right]$, the zonal advective feedback term $\left[\mathrm{ZA} ;-u^{\prime}(\partial \bar{T} / \partial x)\right]$, the Ekman pumping feedback term $\left[\mathrm{EK} ;-v^{\prime}(\partial \bar{T} / \partial y)-w^{\prime}(\partial \bar{T} / \partial z)\right]$, the mean circulation damping term [MC; $\left.-\bar{u}\left(\partial T^{\prime} / \partial x\right)-\bar{v}\left(\partial T^{\prime} / \partial y\right)-\gamma \bar{w}\left(T^{\prime} / H_{m}\right)\right]$, and the thermodynamical damping term (TD; $Q$ ). In this paper, we focus on the two main positive feedback terms: the TH and ZA, which are crucial for ENSO development.

\section{Identification of the spatiotemporal types of EI Niño and La Niña events}

The 24 El Niño events and 21 La Niña events during 1921-2018 varied in terms of their spatial patterns and temporal evolutions, and they had a wide range of durations, amplitudes, and locations of mature SSTA centers (Figs. 1 and 4), reflecting the spatial and temporal diversity of ENSO events (Capotondi et al. 2015; Timmermann et al. 2018). Among them, four events with ambiguous spatial features were excluded in this study. Generally, one El Niño or La Niña event only has a clear monthly mean SSTA center in the equatorial Pacific during the mature stage, but the three El Niño events (the 6th, 1953/54; the 11th, 1969/70; and the 22nd, 2006/07) and the one La Niña event (the 2nd, 1933/34) had two distinguishable positive and negative SSTA centers coexisting in the central and eastern equatorial Pacific, respectively.

For the remaining $21 \mathrm{El}$ Niño events and 20 La Niña events, the difference in duration from the shortest (5 months) to the longest ( 32 months) was significant, which was related to the $2-7$-yr interannual variability of ENSO. Figure 2a shows the wavelet power spectra of the Niño-3.4 index. The periodicity of ENSO spreads widely on interannual time scales, but as revealed by previous studies (e.g., Rasmusson et al. 1990; An and Wang 2000; Kao and Yu 2009), significant power is mainly concentrated in the two interannual bands: the 1.5-3-yr (QB) band and the 3-7-yr (LF) band. Moreover, although the periodicity of ENSO was constantly changing, it always had no more than one significant instantaneous local 

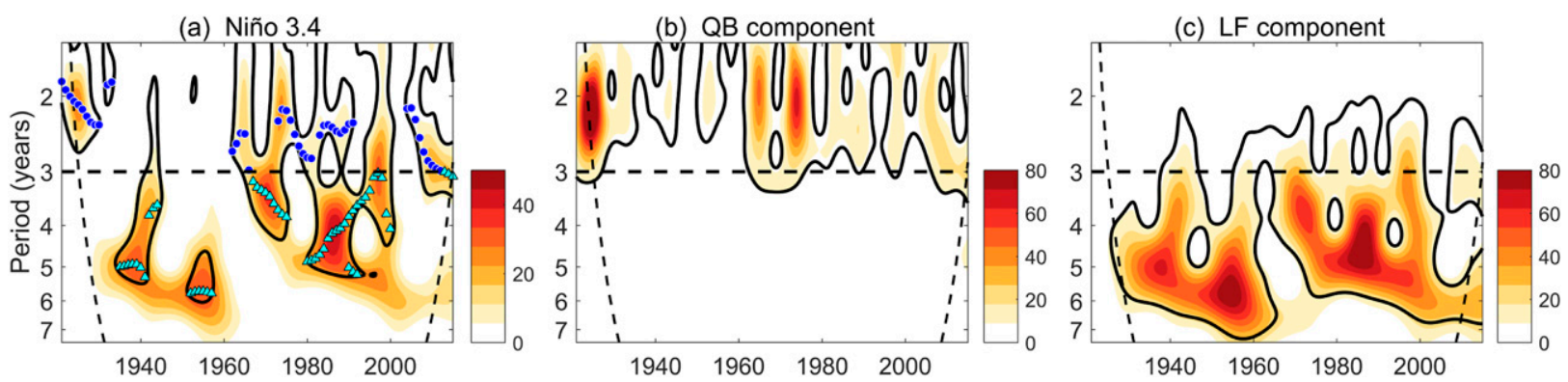

FIG. 2. Wavelet power spectra of (a) the Niño-3.4 index, (b) the QB component, and (c) the LF component. The black contour denotes statistical significance at the $95 \%$ confidence level. The blue circles and light blue triangles denote the significant instantaneous local maxima of power in the QB and LF bands, respectively.

maximum of power in each band. The QB and LF bands were suggested to be connected with the spatial types of ENSO (Kao and Yu 2009; Ren et al. 2013; Wang and Ren 2017). However, the two interannual bands are sometimes simultaneously significant as interannual periods; how to measure the relative strength of the QB and LF components is the key to examining whether ENSO characteristics are connected with the QB and/ or LF variability.

To extract the QB and LF components from the SSTAs, the Niño-3.4 index time series are decomposed into nine IMF-like components with decreasing frequencies through the EEMD method. Here, the amplitude of the white noise series used for EEMD is 0.25 times the standard deviation of the Niño-3.4 index. Among these components, the 3rd, 4th, and 5th components (C3-C5) are on the 2-7-yr ENSO time scale (Figs. 2b,c). The C3 with significant periods of 1.5-3 years can be regarded as the QB component, and both the $\mathrm{C} 4$ and the $\mathrm{C} 5$ with significant periods of 3-7 years are combined to reproduce the LF component. The time series reconstructed by the QB and LF components are well correlated with the Niño-3.4 index (Fig. 1), and the correlation coefficient is greater than 0.9 . Hence, the QB and LF components are effectively extracted from the original Niño-3.4 index and can represent the main interannual variability of ENSO.

The respective time series of the $\mathrm{QB}$ and LF components are shown in Fig. 3. The amplitudes of the two temporal components varied remarkably, which might be affected by changes in the mean state or external forcings (e.g., Vimont et al. 2003; Bejarano and Jin 2008; Chen et al. 2015; Wang et al. 2017; Cai et al. 2018; Xie and Jin 2018). Accompanied by such amplitude changes, manifestations of the two interannual components in $\mathrm{El}$ Niño and La Niña events were different. In seven El Niño events (the 1st, 2nd, 8th, 9th, 18th, 21st, and 23rd) and seven La Niña events (the 1st, 7th, 9th, 15th, 16th, 17th, and 20th), the amplitude of the QB component was obviously higher than that of the LF component, and the time when each of these events reached their single peak was always close to the peak time of their QB components. In other words, these events were QB-dominated events. The remaining events were dominated by the LF component, but due to the different persistence of the QB and LF components, the LF-dominated events had two types depending on whether one or more El Niño and La Niña peaks were observed during the positive and negative phase of the LF component, respectively. The first type of LF-dominated events had a single peak (the 3rd, 7th, 12th, 15th, 17th, 19th, 20th, and 24th El Niño events and the 4th, 5th, 11th, and 13th La Niña events) that was close to the peak time of the LF component, similar to the QB-dominated events. The second type included events with double or triple peaks (the 4th and 16th El Niño events and the 3rd, 6th, 8th, 12th, and 14th La Niña events) or two adjacent El Niño or La Niña events with short time intervals (the 5th-6th,
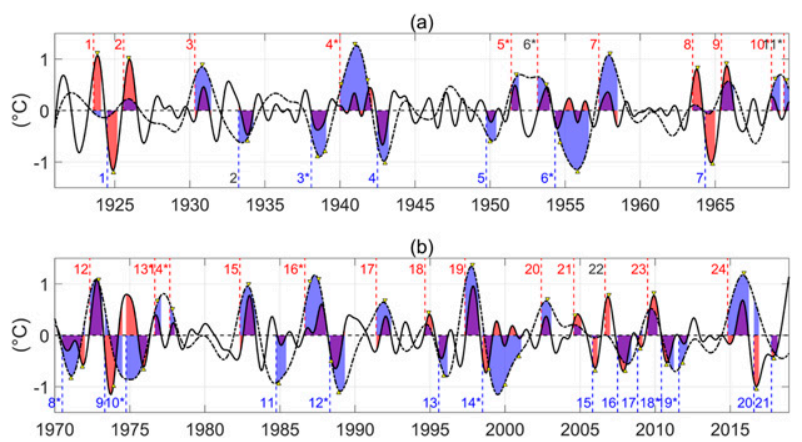

FIG. 3. (a),(b) Time series of the QB component (black solid line) and LF component (black dashed line) of the Niño-3.4 index. The red and blue dashed lines denote the beginning times of El Niño and La Niña events, respectively. The yellow triangles denote the peaks of the El Niño or La Niña events. The red and blue shadings denote the strength of the QB and LF components in the events, respectively. The numbers followed by an asterisk denote the LF-mixing El Niño and La Niña events. 

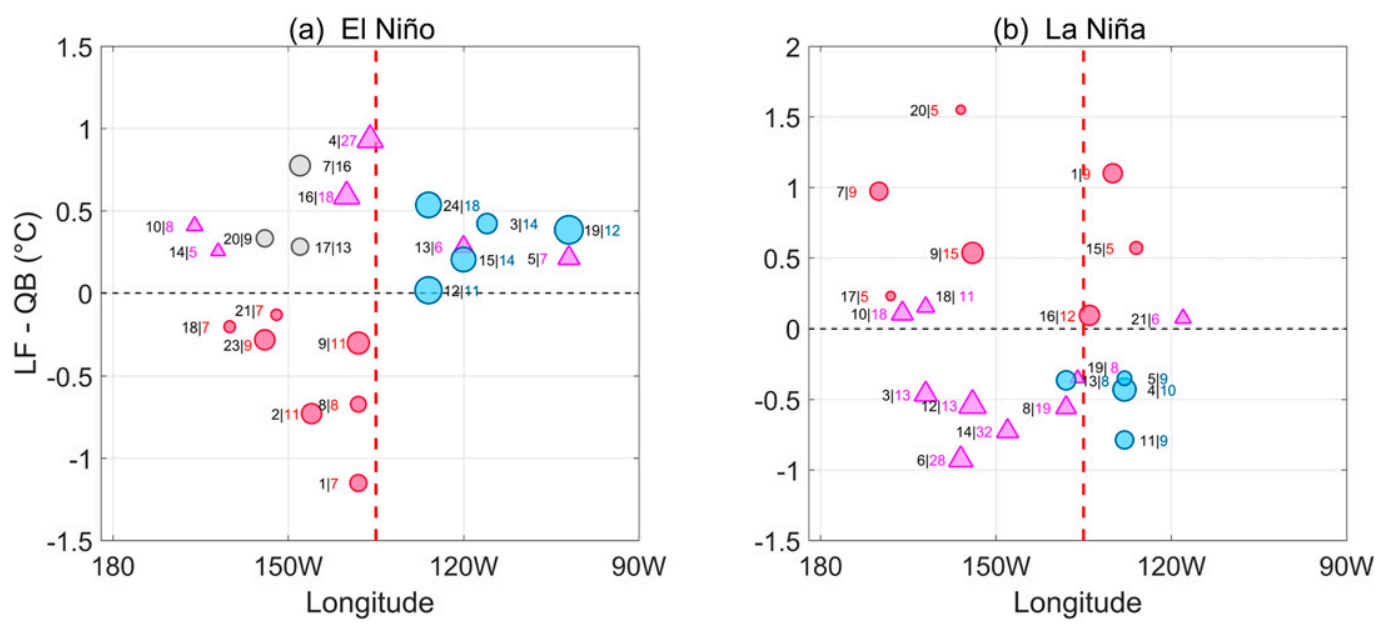

FIG. 4. Scatter diagrams showing the difference between the LF and QB components of the Niño-3.4 index vs (a) the longitude of the positive SSTA center in the equatorial Pacific at the peak times of El Niño events and (b) the longitude of the negative SSTA center in the equatorial Pacific at the peak times of La Niña events. The red dashed line is located at $135^{\circ} \mathrm{W}$. The purple-filled triangles represent the LF-mixing events, the circles represent the singlepeak events, the red-filled circles represent the QB-CP events, and the blue-filled circles represent LF-EP events. The sizes of markers represent the strength $(\mathrm{QB}+\mathrm{LF})$ at the peak times of El Niño and La Niña events. For the number pairs near each circle or triangle, the left number is the serial number of an El Niño or La Niña event, and the right number is the duration in months of an El Niño or La Niña event.

10th-11th, and 13th-14th El Niño events and the 9th10th and 18th-19th La Niña events). The peaks of these LF-dominated events were also significantly affected by QB or higher-frequency variabilities, which had more uncertainties than the first type.

Bejarano and Jin (2008) and Xie and Jin (2018) mentioned that the theoretical LF mode has an EP ENSO-like spatial pattern, while the theoretical QB mode has a CP ENSO-like spatial pattern. Hence, whether the QB- and LF-dominated El Niño or La Niña events also have connections with their spatial types was examined (Fig. 4). Here, we used the difference between the LF and QB components averaged from 1 month before to 1 month after the peak time of the El Niño or La Niña event to measure the relative strength of the two components during the mature stage of the El Niño or La Niña event.

For all seven QB-dominated El Niño events (marked by the red-filled circles in Fig. 4a), their positive SSTA centers were located west of $135^{\circ} \mathrm{W}$ during the mature stage, which is a typical feature of the CP ENSO type. Therefore, by connecting their temporal properties with spatial features, these events can be identified as "QBdominated CP ENSO-like" (QB-CP) El Niño events. For the eight single-peak LF-dominated El Niño events, five of them (marked by blue-filled circles in Fig. 4a) had a positive SSTA center east of $135^{\circ} \mathrm{W}$, which was similar to the EP ENSO, and can be referred to as the "LF-dominated EP ENSO-like" (LF-EP) El Niño events, except for the 7th (1957/58), the 17th (1991/92), and the 20th (2002/03) events. Moreover, when LF-EP El Niño events occurred, both the QB and the LF components had high amplitudes and easily led to extremely strong intensities. The four most powerful El Niño events in recent decades (1972/73, 1982/83, 1997/ 98, 2015/16) were all the LF-EP type. The QB-CP and LF-EP El Niño events also had different durations (Fig. 4a). The former, with a duration of 7-11 months, is significantly shorter than the latter, with a duration of 11-18 months.

The remaining six LF-dominated El Niño events with double or triple El Niño peaks during the positive phase of their LF components (marked by purple-filled circles in Fig. 4a) had ambiguous spatial features. Their SSTA centers were widely scattered in the equatorial Pacific. Meanwhile, their duration was extremely short or extremely long. The two long events with double or triple peaks lasted 18 and 27 months, respectively, whereas the other four short events lasted only 5-8 months and always occurred in pairs. The time scales of these events were regulated by the LF variability but were significantly affected by the QB or higher-frequency variability. Hence, these events were referred to as the "LF-dominated mixing" (LF-mixing) El Niño events.

Previous studies have mentioned that the SSTA patterns of La Niña are not as distinguishable as those of El Niño (Kug et al. 2009; Kug and Ham 2011; Ren and Jin 2011). The majority of La Niña events had negative 
TABLE 1. Features of the three spatiotemporal types of El Niño and La Niña.

\begin{tabular}{|c|c|c|c|c|c|}
\hline \multirow[b]{2}{*}{ Types } & \multirow{2}{*}{$\begin{array}{l}\text { No. of peaks } \\
\text { or valleys }\end{array}$} & \multicolumn{2}{|c|}{ Amplitude } & \multirow{2}{*}{$\begin{array}{l}\text { Longitude of the mature } \\
\text { SSTA center }\end{array}$} & \multirow[b]{2}{*}{ Duration } \\
\hline & & QB component & LF component & & \\
\hline QB-CP & 1 & High & Low & West of $135^{\circ} \mathrm{W}$ & Short \\
\hline LF-EP & 1 & High & High & East of $135^{\circ} \mathrm{W}$ & Long \\
\hline LF-mixing & $\geq 1$ & Low & High & Scattered & $\begin{array}{c}\text { Extremely short or } \\
\text { extremely long }\end{array}$ \\
\hline
\end{tabular}

SSTA centers west of $120^{\circ} \mathrm{W}$ (Fig. 4b), which were generally located more westward than the centers of El Niño events. However, regardless of the LF-mixing La Niña events that had ambiguous features like the LFmixing El Niño events, distinctions between the QBdominated and the remaining LF-dominated La Niña events were similar to those between the QB-CP and LF-EP El Niño events. The SSTA centers of all four remaining LF-dominated La Niña events were concentrated east of $140^{\circ} \mathrm{W}$, similar to that of the LF-EP El Niño. More than half of the QB-dominated La Niña events (4 out of 7) had mature SSTA centers west of $150^{\circ} \mathrm{W}$, which was similar to the QB-CP El Niño. The other three events were also centered close to $135^{\circ} \mathrm{W}$, which is the boundary separating the QB-CP and LF-EP El Niño types. Therefore, these La Niña events could also be categorized into the QB-CP and LF-EP types.

Table 1 lists the abovementioned individual features of the three types of El Niño and La Niña events. The activities of the QB and LF components are evidently connected with the observed El Niño and La Niña events. For the QB-CP and LF-EP El Niño and La Niña types, the spatial and temporal features are highly related. That is, two independent ENSO modes may coexist in nature.

\section{Spatiotemporal diversity of ENSO resulting from the $Q B$ and $L F$ modes}

We further examined the spatial structures and temporal evolutions of the QB-CP and LF-EP El Niño and La Niña types. Here, the total number of 7, 5, 7, and 4 events were used to make composites for the QB-CP El Niño, LF-EP El Niño, QB-CP La Niña, and LF-EP La Niña types, respectively, based on the peak time of each event. In addition, the LF-mixing events with no regular spatial features and complex life cycles are not the focus of this paper and will thus be further studied in the future.

At the mature stage of El Niño, the QB-CP and LFEP types have significantly distinct spatial structures. On the one hand, the maximum of the positive SSTAs in the QB-CP El Niño type is located at approximately $150^{\circ} \mathrm{W}$ on the equator (Fig. 5a), while that in the LF-EP El Niño type is shifted eastward by approximately $35^{\circ}$ and is located at approximately $115^{\circ} \mathrm{W}$. On the other hand, the LF-EP El Niño type is much stronger than the QB-CP El Niño type and has a larger significant area in the central eastern tropical Pacific, which not only covers the main significant area of the QB-CP El Niño but also extends to the eastern boundary of the tropical Pacific. Correspondingly, the SSTA structures of the LF-EP and QB-CP La Niña during the mature stage are nearly opposite to those of the LF-EP and QB-CP El Niño respectively, although the LFEP La Niña are not as strong as the LF-EP El Niño. Therefore, both El Niño and La Niña have a QB component that is intimately connected with a CP ENSO-like SSTA pattern, while the LF component tends to correspond to an EP ENSO-like spatial pattern.

Figure 6 shows temporal evolutions of the observed SSTA composites in the QB-CP and LF-EP El Niño. Since the main areas of the QB-CP (LF-EP) events are located within the Niño-3.4 (Niño-3) region, the QB and LF components of the Niño-3.4 (Niño-3) index are also shown in Fig. 6c (Fig. 6d). For the QB-CP El Niño (Figs. 6a,c), its positive phase starts approximately 7 months before the El Niño peak and disappears approximately 6 months after the peak, lasting for a total of approximately 1 year; this phase is followed by a relatively weak negative phase that also lasts for approximately 1 year. Furthermore, the QB component of the Niño-3.4 index is very close to that of the original Niño-3.4 index; however, the LF component is much weaker than the $\mathrm{QB}$ component. At the peak time of the QB-CP El Niño, the QB component $\left(0.75^{\circ} \mathrm{C}\right)$ accounts for $58 \%$ of the Niño- 3.4 index $\left(1.30^{\circ} \mathrm{C}\right)$, while the LF component $\left(0.23^{\circ} \mathrm{C}\right)$ accounts for only $18 \%$. Clearly, the QB mode coupled with the CP ENSO-like spatial pattern makes a major contribution to the QB-CP El Niño and significantly dominates the characteristics of the QBCP El Niño.

For the LF-EP El Niño, as seen in Figs. $6 \mathrm{~b}$ and $6 \mathrm{~d}$, its positive phase lasts only a few months longer than that of the QB-CP El Niño; however, its negative phase lasts much longer and appears to linger. There is also significant asymmetry between the strong positive phase and the weak negative phase of the LF-EP El Niño type, and their spatial structures are different. The LF-EP El Niño 
(a) QB-CP EI Niño : SSTA

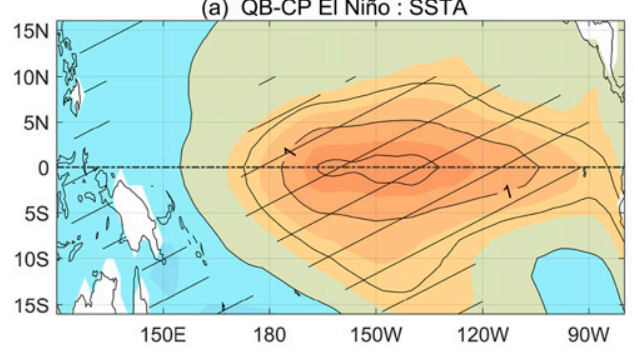

(c) QB-CP La Niña : SSTA

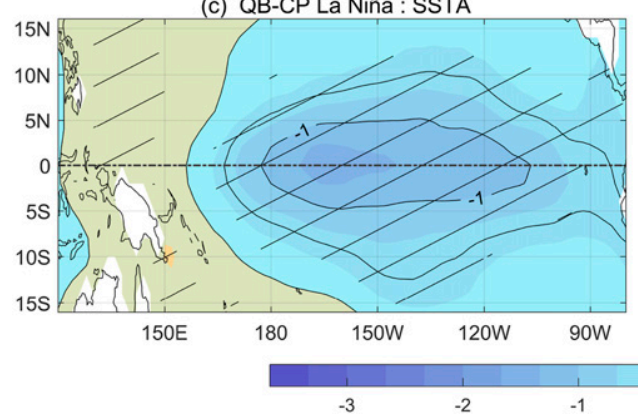

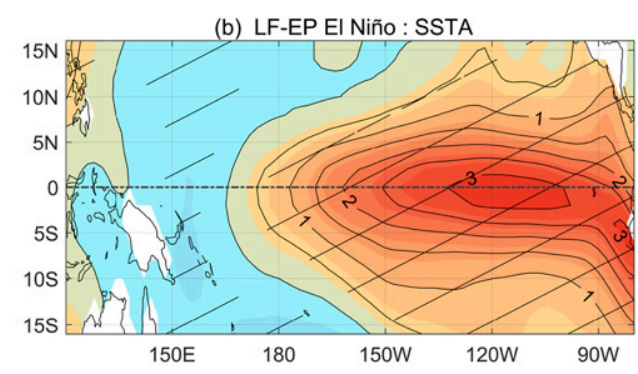

(d) LF-EP La Niña : SSTA

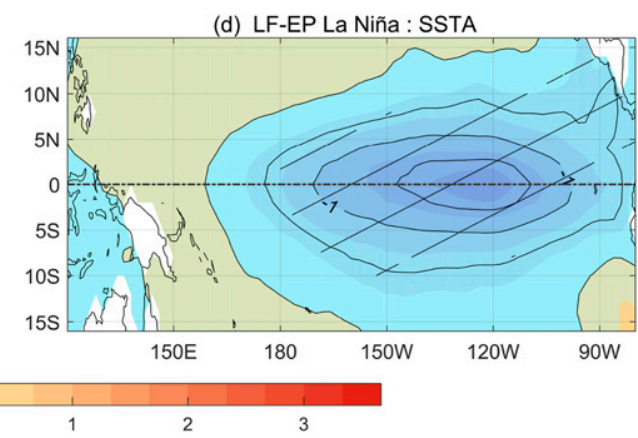

FIG. 5. Composites of SSTA (units: ${ }^{\circ} \mathrm{C}$ ) for (a) QB-CP El Niño, (b) LF-EP El Niño, (c) QB-CP La Niña, and (d) LF-EP La Niña events at the peak time. The contour interval is $0.5^{\circ} \mathrm{C}$. Hatched areas indicate values exceeding the $90 \%$ confidence level determined using a two-tailed Student's $t$ test. The black dashed line represents the equator.

has a strong positive SSTA center located at approximately $115^{\circ} \mathrm{W}$ during the mature stage, but its following negative phase is characterized by a weak CP La Niña until its first negative peak is almost completely damped. The Niño-3 index in LF-EP El Niño is not close to either the QB or the LF components; however, it is close to their combined value (Fig. 6d). Both components are strong, and their peaks almost coincide with the peak of El Niño. At the peak month of the LF-EP El Niño, the Niño-3 index is $2.58^{\circ} \mathrm{C}$, while the QB and LF components are $0.82^{\circ}$ and $1.24^{\circ} \mathrm{C}$, respectively, which account for $32 \%$ and $48 \%$, respectively, of the Niño-3 index. Thus, the LF mode coupled with the EP ENSO-like spatial pattern is dominant and plays a major role in the LF-EP El Niño, and the QB mode is still active with its amplitude being comparable to that of the QB-CP El Niño. Due to the different persistence of the QB and LF components, the first valley of the negative phase that occurs 12 months after the El Niño peak is almost entirely contributed by the QB component; at this time, the LF component is damped to become neutral.

The QB-CP La Niña type has an almost symmetric pattern with the QB-CP El Niño in terms of its amplitude and phase as well as its QB and LF components, as seen in Figs. 7a and 7c and compared with Figs. 6a and $6 c$, although their spatial patterns are somewhat different. However, the temporal evolution of the LF-EP La
Niña type is different from that of the LF-EP El Niño type, as shown in Figs. $7 \mathrm{~b}$ and $7 \mathrm{~d}$ and compared with Figs. $6 \mathrm{~b}$ and $6 \mathrm{~d}$. Clearly, the LF mode in the LF-EP La Niña type is strong, but the QB mode is much weaker with its negative peak several months away from that of the LF mode. Such a QB mode does not have a significant effect on spatial patterns of the LF-EP La Niña, which is definitely controlled by the LF mode.

The QB and LF components in observations are coupled with EP and CP ENSO-like spatial patterns, respectively. The 1.5-3-yr period and the corresponding CP ENSO-like spatial pattern are characteristics of the QB mode, while the 3-7-yr period and the EP ENSO-like spatial pattern are characteristics of the LF mode. Such two independent modes with changing amplitudes coexist in the tropical Pacific, which is consistent with the theorical results obtained from an intermediate coupled model that the two modes are sensitive to changes in the basic state and can coexist in the tropical Pacific under a certain parameter range (Bejarano and Jin 2008; Xie and Jin 2018). Previous studies have suggested that the two modes are related to the observed EP and CP ENSO-type events, respectively (Ren and Jin 2013; Ren et al. 2013; Wang and Ren 2017; Timmermann et al. 2018). However, in this study, we have shown that the spatiotemporal characteristics of the observed El Niño and La Niña events depend on the two ENSO modes simultaneously. Relative activity 

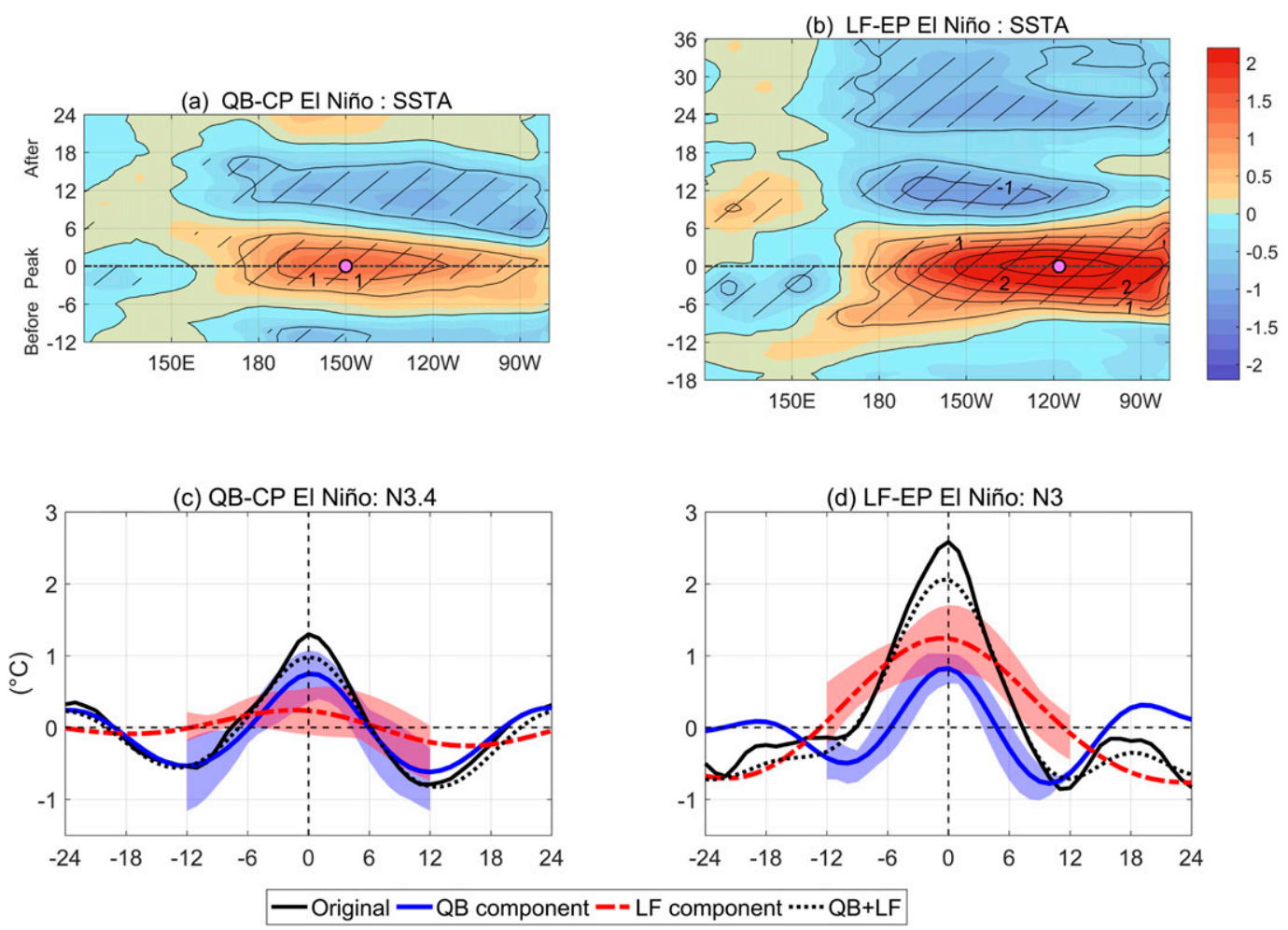

FIG. 6. (a),(b) Longitude-time cross sections of composites of the equatorial Pacific SSTAs (units: ${ }^{\circ} \mathrm{C}$ ) averaged over $5^{\circ} \mathrm{N}-5^{\circ} \mathrm{S}$ for the (a) QB-CP El Niño and (b) LF-EP El Niño. Time on the $y$ axis is in months. The contour interval is $0.5^{\circ} \mathrm{C}$. Hatched areas indicate values exceeding statistical significance at the $90 \%$ confidence level in terms of a two-tailed Student's $t$ test. The black dashed lines represent the peak times of El Niño, and the purple circular dots represent the equatorial SSTA centers. (c) Composite evolutions of the Niño-3.4 index and the corresponding QB and LF components, as well as their combination, for the QB-CP El Niño. (d) As in (c), but showing the Niño-3 index for the LF-EP El Niño. Upper and lower boundaries of the light red (blue) shading indicate the maximum and minimum of the LF (QB) component in the red (blue) lines among the events used for composite, respectively. Time on the $x$ axis is months.

changes and phase differences of the two modes significantly contribute to the spatiotemporal diversity of the observed ENSO events.

We further examined the associated anomalies of zonal surface wind stress (Taux) and $20^{\circ} \mathrm{C}$ isotherm depth (D20), which is used to depict the thermocline variation. Due to the limited length of GFDL data, only five QB-CP El Niño events (1963/64, 1965/66, 1994/95, 2004/05, 2009/10) and three LF-EP El Niño events (1972/73, 1982/83, 1997/98) that occurred during 19612015 were selected for the composite analysis, while La Niña events without enough LF-EP type of events during 1961-2015 were not examined. In both El Niño types, the composite atmospheric response is coupled with the SSTAs, as seen in Figs. 8a and 8b. At the peak time of both El Niño types, it is clear that the zero line of Taux anomalies on the equator is close to the corresponding positive SSTA center. Meanwhile, positive Taux anomalies in the LF-EP El Niño type occupy a larger area in the tropical Pacific and are much stronger than those in the QB-CP El Niño type, which is in line with the intensity of the LF-EP El Niño type. The eastward extension of the positive wind stress anomalies in the western Pacific tend to be connected with a longer period of ENSO (An and Wang 2000). Differences in the D20 anomalies between the two types are also significant, as seen in Figs. 8c and 8d, although the positive anomaly centers of the two types are both located east of $120^{\circ} \mathrm{W}$ on the equator at the peak time of El Niño. Compared with the LF-EP El Niño type, the QB-CP El Niño type has a larger area of positive D20 anomalies in the central Pacific. Meantime, its negative anomalies in the western Pacific are relatively weak, indicating that its zonal reversal structure is not as clear as that in the LF-EP El Niño type.

Figure 9 shows the time evolutions of the Taux anomalies and D20 anomalies. Similar to the SSTAs, the difference in the interannual time scale between the two 

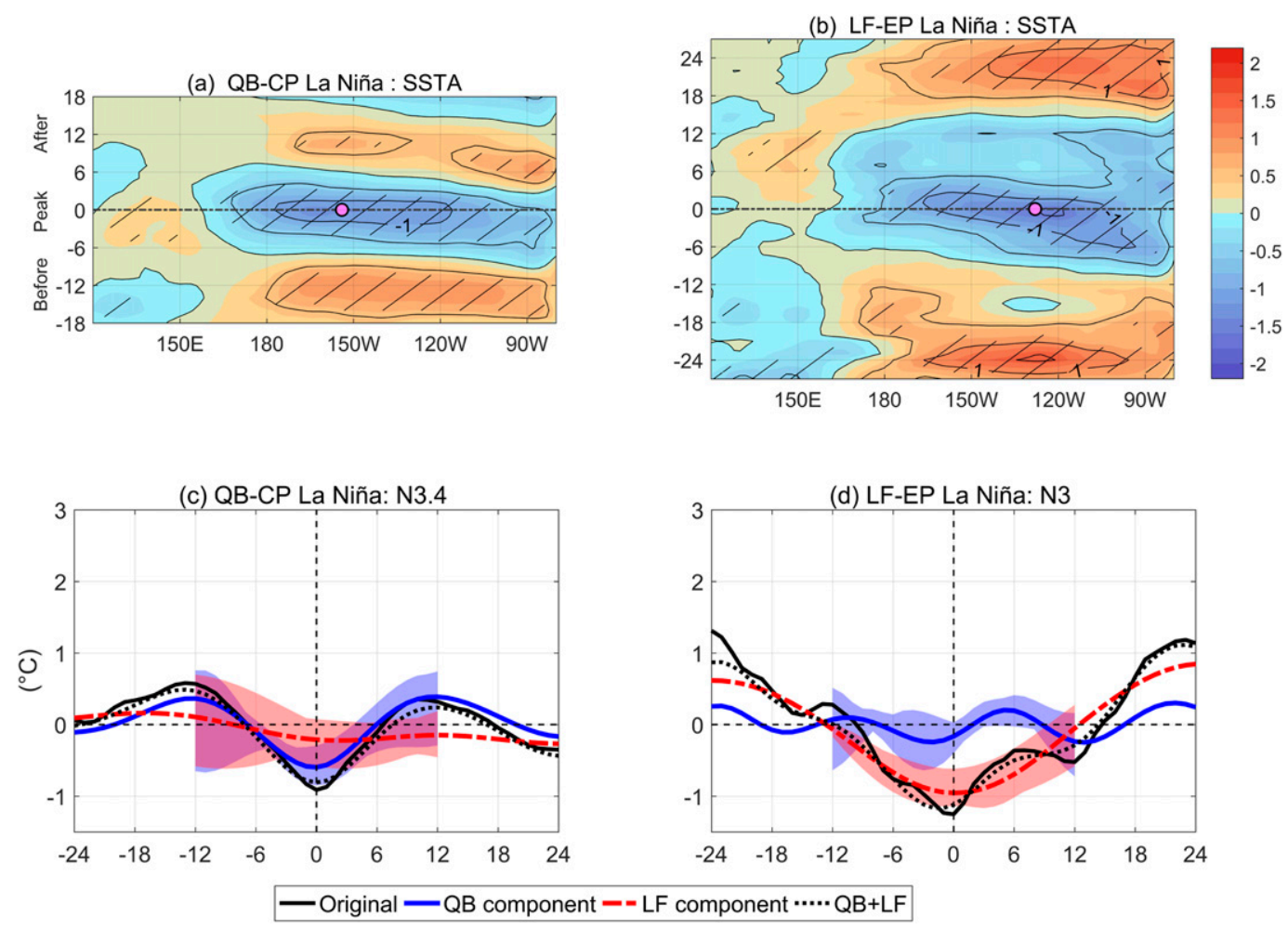

FIG. 7. As in Fig. 6, but for (a),(c) QB-CP La Niña and (b),(d) LF-EP La Niña.

El Niño types is significant in the Taux and D20 anomalies. At the development stage of the QB-CP El Niño type, the Taux anomalies in the western Pacific are weakly negative until 6 months before the El Niño peak, and the positive Taux anomaly center is located west of the date line and basically remains in situ during the positive phase. The positive D20 anomalies in the QB-CP El Niño type are weak but basinwide, beginning to exceed $5 \mathrm{~m}$ in the western Pacific approximately 12 months before the peak and extending to the eastern boundary after 5 months. There are nearly symmetrical distributions of the Taux and D20 anomalies between the positive phase and its following negative phase. However, the features of the two variables are different in the LF-EP El Niño type. Its development stage begins earlier than that of the QBCP El Niño type. The positive Taux anomalies in the LFEP El Niño have occupied the entire western Pacific 12 months before the El Niño peak, approximately 6 months earlier than those in the QB-CP El Niño type, and have a significant eastward propagation at the development stage, finally reaching $120^{\circ} \mathrm{W}$ at the El Niño peak. The positive D20 anomalies tend to appear early in the western Pacific and exhibit a slow eastward propagation, which may be caused by the internal dynamic ocean adjustment and is different from the eastwardpropagating oceanic Kelvin waves. For the LF-EP El
Niño type, the asymmetry between the positive and following negative phases is conspicuous. During the development stage of the following La Niña, the negative Taux anomalies are not strong enough and are only distributed west of $150^{\circ} \mathrm{W}$, and the negative D20 anomalies are centered at $150^{\circ} \mathrm{W}$, making it difficult to produce a strong discharge process.

The TH and ZA are well known as the two major positive feedback terms during the ENSO developing stage, and they play key roles in the phase transition of ENSO (An et al. 1999; Jin and An 1999; An and Jin 2001). Previous studies have revealed that individual contributions of the two terms to the ENSO diversity are different and there is no doubt that the $\mathrm{TH}$ are dominant in the EP ENSO type and LF mode, while whether the $\mathrm{ZA}$ is the leading positive feedback in the CP ENSO type and QB mode remains controversial (Bejarano and Jin 2008; Kug et al. 2009; Ren and Jin 2013; Xie et al. 2015; Xie and Jin 2018). Here, we quantitatively investigate the roles of the two tendency terms in the QB-CP and LF-EP El Niño types based on heat budget analysis. As seen in Fig. 10, for both El Niño types, before the El Niño peak, the TH and ZA terms have different strength and phases, where the TH is significantly stronger than the ZA after the 6 months before the peak and makes a major positive contribution to the development of 
(a) QB-CP El Niño : TauxA

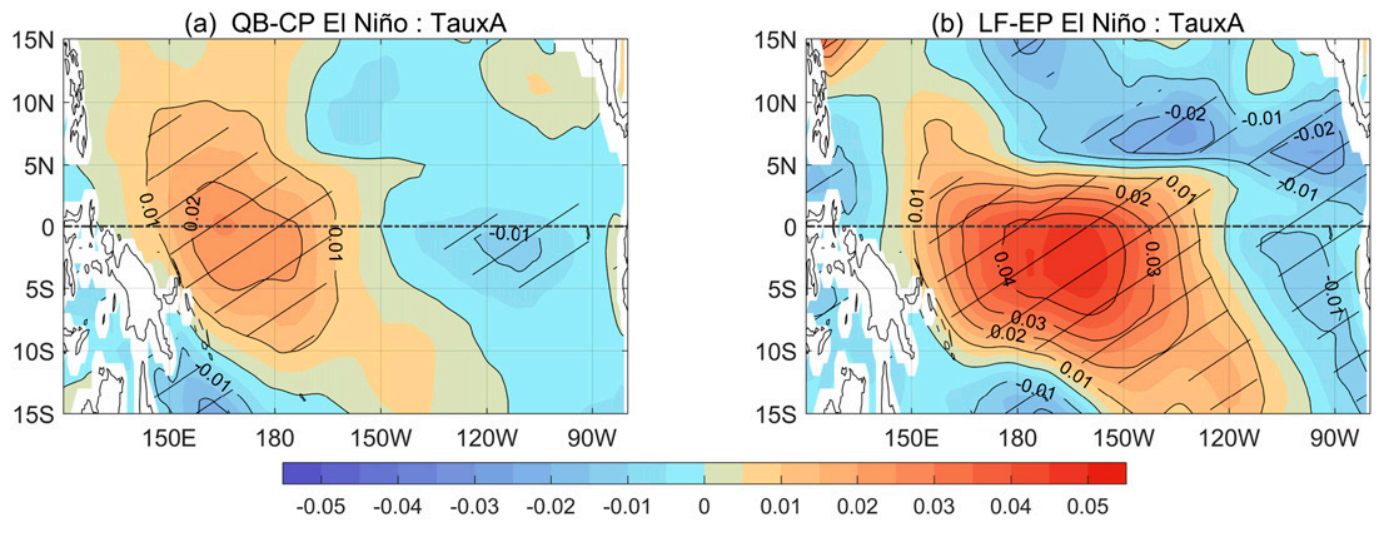

(c) QB-CP EI Niño : D20A

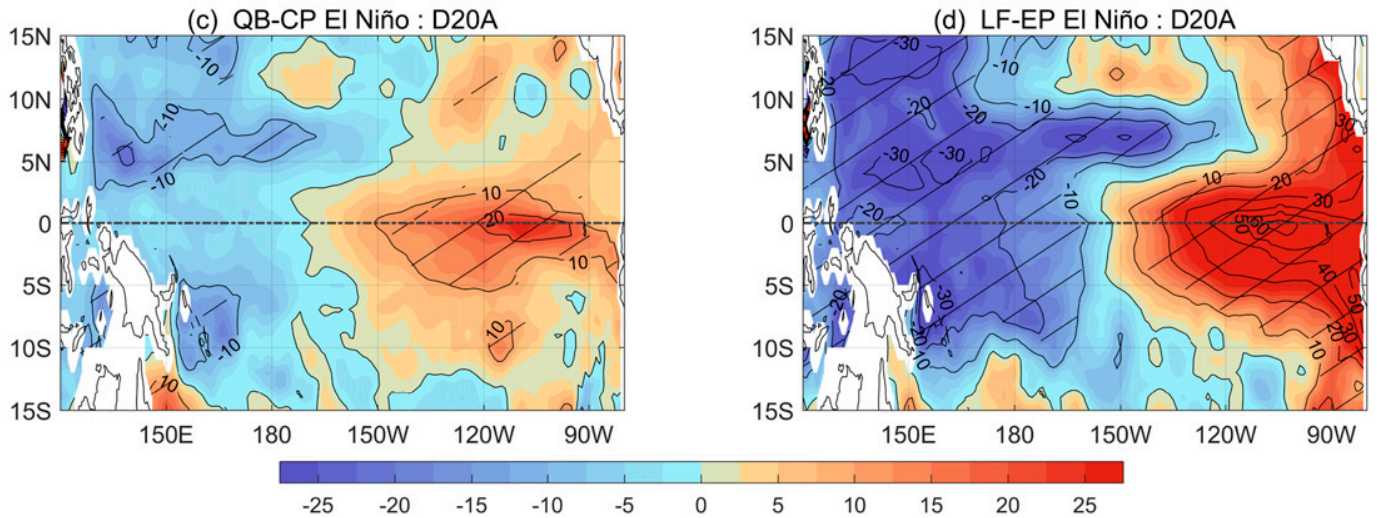

FIG. 8. (a),(b) Composites of Taux anomalies (units: $\mathrm{N} \mathrm{m}^{-2}$; contour interval: $0.01 \mathrm{~N} \mathrm{~m}^{-2}$ ) for the (a) QB-CP El Niño and (b) LF-EP El Niño events at the peak time. (c),(d) As in (a) and (b), but for D20 anomalies (units: m; contour interval: $10 \mathrm{~m}$ ). Hatched areas indicate statistical significance at the $90 \%$ confidence level using a two-tailed Student's $t$ test. The black dashed lines represent the equator.
El Niño, while the ZA term turns positive earlier than the $\mathrm{TH}$ term in the initial stage and thus, due to a longer duration before the peak, is probably more important for the initiation of El Niño events. This result indicates that such timing should be taken into account when comparing the relative contributions of the $\mathrm{ZA}$ and $\mathrm{TH}$ terms to El Niño development. It can be noticed that the residual part is large during the decay stage of QB-CP El Niño, probably associated with the uncertainties in ocean currents in the reanalysis dataset (Ren and Jin 2013). We calculate the ratio of the time-averaged ZA and $\mathrm{TH}$ terms in the development and decay stages of $\mathrm{El}$ Niño (Fig. 11), which can measure the relative importance of the accumulated effects of the two terms in the two El Niño types. The ratio of ZA/TH is less than 1.0 for the two El Niño types (Fig. 11a), which means that the TH term makes the main positive contribution to the development of El Niño, whether in the QB-CP or LFEP type. The ratio value in the QB-CP El Niño is always larger than that in the LF-EP El Niño, although different time domains are selected for time averaging. Hence, the ZA term plays a relatively more important role in the QB-CP El Niño than in the LF-EP El Niño, which is consistent with the theoretical results in Bejarano and Jin (2008) and gives evidence that the QB and LF modes have distinctions in their dynamical processes, although the difference between the $\mathrm{TH}$ and $\mathrm{ZA}$ terms in the growth of traditional EP and CP El Niño events may be overestimated in previous studies (Kug et al. 2009; Xie and Jin 2018). In the decay stage of the two El Niño types (Fig. 11b), the ZA term turns negative earlier than the TH term, makes the main contributions to the phase transitions of both El Niño types. In addition, the accumulated effect of the TH term turns negative earlier in the LF-EP El Niño than in the QB-CP El Niño, which is mainly due to the phase differences between the TH term and the ENSO SSTAs in the two El Niño types. The peak of the TH term is obviously ahead of the peak of the LF-EP El Niño, but it is close to the peak of the QB-CP El Niño (Figs. 10e,f). This feature has been mentioned in Bejarano and Jin (2008), which is suggested to be an important factor that affects the growth 
(a) QB-CP El Niño : TauxA

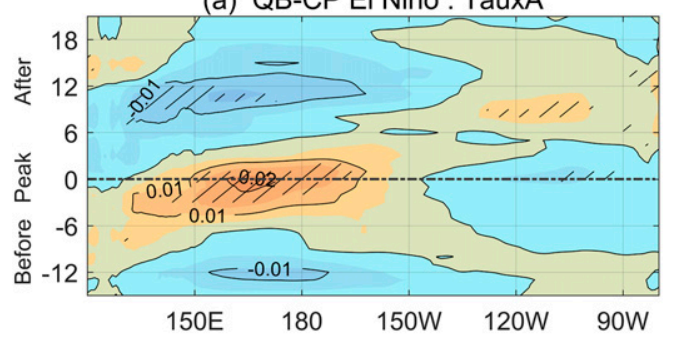

(b) LF-EP EI Niño : TauxA

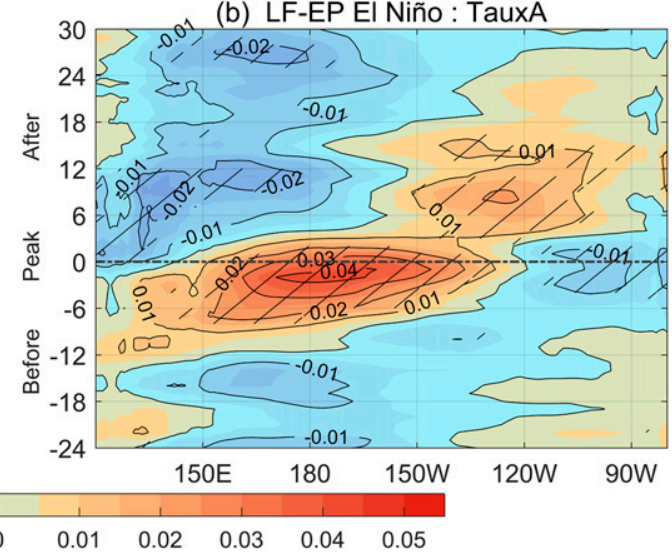

(d) LF-EP El Niño : D20A

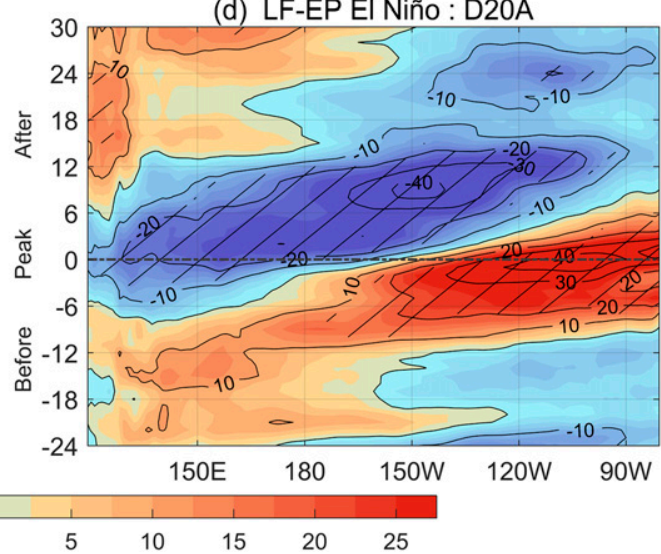

FIG. 9. (a),(b) Time evolution of composites of the equatorial Pacific Taux anomalies (units: $\mathrm{N} \mathrm{m}^{-2}$; contour interval: $0.01 \mathrm{~N} \mathrm{~m}^{-2}$ ) averaged over $5^{\circ} \mathrm{N}-5^{\circ} \mathrm{S}$ for the (a) QB-CP El Niño and (b) LF-EP El Niño. (c), (d) As in (a) and (b), but for D20 anomalies (units: $\mathrm{m}$; contour interval: $10 \mathrm{~m}$ ) averaged over $2^{\circ} \mathrm{N}-2^{\circ} \mathrm{S}$. Time on the $y$ axis is in months. Hatched areas indicate the values that are statistically significant at the $90 \%$ confidence level using a two-tailed Student's $t$ test. The black dashed lines represent the peak month.

and phase transition mechanisms of the $\mathrm{QB}$ and $\mathrm{LF}$ modes. When the tendency term is in phase with the ENSO SSTAs like the TH term in the QB-CP El Niño, it mainly contributes to the ENSO growth rather than to the phase transition. Therefore, further connected to the relative strength of the QB and LF modes in the two El Niño types, it could be inferred that the TH dominates the growth of the QB and LF modes and contributes to the phase transition of the LF mode, while the ZA plays a relatively more important role in the QB mode than in the LF mode and makes the main contributions to the phase transitions of the two modes.

\section{Summary and discussion}

Since ENSO features a widely spread interannual time scale, previous studies have mainly distinguished it into an LF band and a secondary QB band (e.g., Rasmusson et al. 1990). In this study, the 2-7-yr
ENSO-related variability together with different spatial patterns was evaluated to examine the key roles of the two ENSO modes in the spatiotemporal diversity of ENSO. Through the EEMD method, the QB and LF components were extracted from the traditional Niño3.4 index. Accordingly, we regrouped El Niño and La Niña events into three types in terms of both the spatial and the temporal features, namely, the QB-CP type, LF-EP type, and LF-mixing type. The LF-mixing type with nonunique SSTA peaks in the positive or negative phase of its LF component is defined to distinguish it from the singlepeak events including both the QB-CP and LF-EP types.

The three types of El Niño have distinct spatiotemporal features. The QB-CP El Niño is dominated by the QB component and characterized by a CP ENSO-like spatial pattern as well as the short duration. In this case, the SSTAs in the equatorial Pacific are constructed by the high-amplitude QB component combined with a powerless LF component and centered in the west of 
(a) QB-CP EI Niño: TH

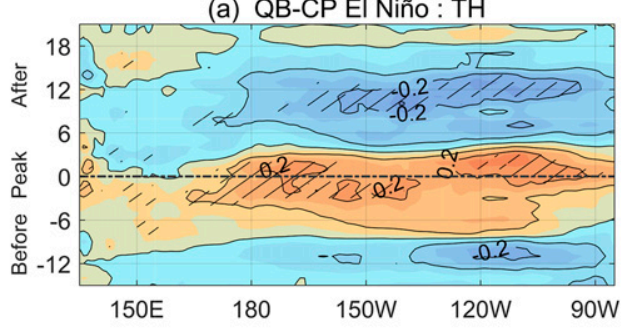

(c) QB-CP EI Niño : ZA

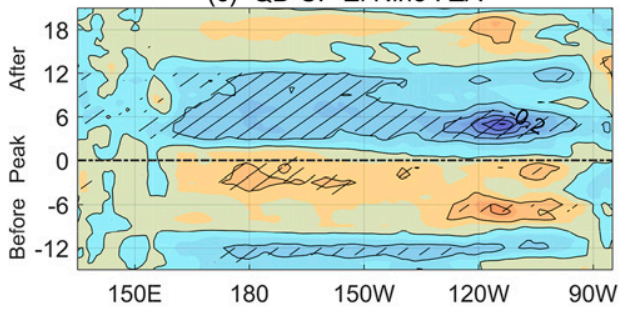

(b) LF-EP El Niño : TH

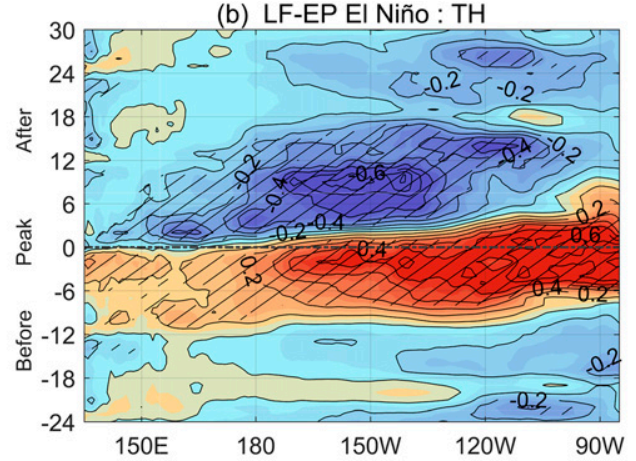

(d) LF-EP El Niño : ZA

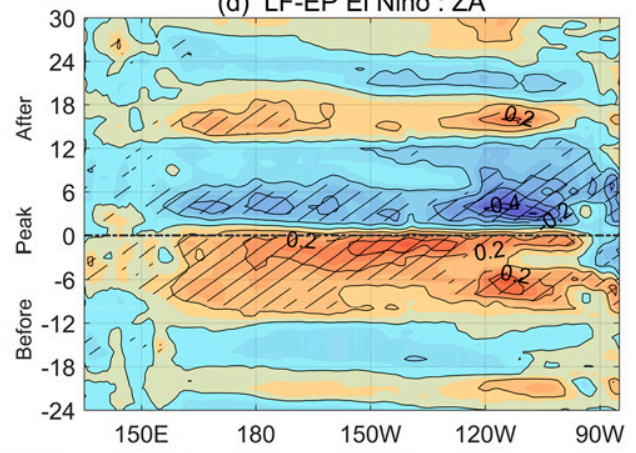

$\begin{array}{lllllllllll}-0.5 & -0.4 & -0.3 & -0.2 & -0.1 & 0 & 0.1 & 0.2 & 0.3 & 0.4 & 0.5\end{array}$

(e) QB-CP El Niño
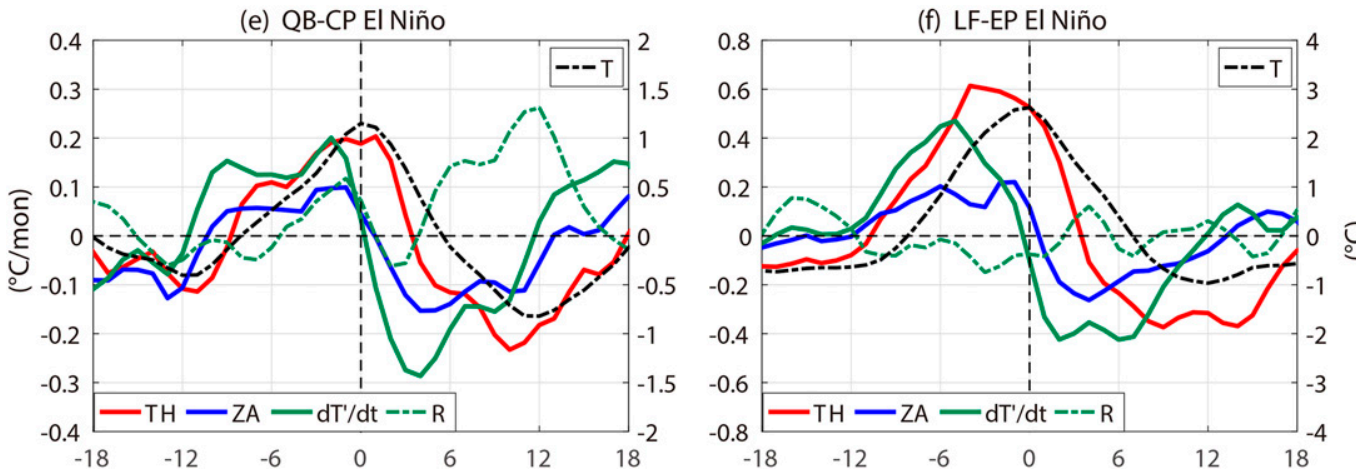

FIG. 10. (top),(middle) As in Fig. 9, but for (a),(b) composites of the TH term averaged over $5^{\circ} \mathrm{N}-5^{\circ} \mathrm{S}$ and (c),(d) composites of the ZA term averaged over $5^{\circ} \mathrm{N}-5^{\circ} \mathrm{S}$. Contour interval is $0.1^{\circ} \mathrm{C}$ month ${ }^{-1}$. (bottom) Composite evolutions of the TH term, ZA term, $d T^{\prime} / d t$, residual term $(R)$, and SSTAs $(T)$ area-averaged over (e) the Niño-3.4 area for the QB-CP El Niño and (f) the Niño-3 area for the LF-EP El Niño.

$135^{\circ} \mathrm{W}$. The LF-EP El Niño is controlled by the LF component and characterized by an EP ENSO-like spatial pattern, with a duration longer than that of the QB-CP type. Different from the manifestations of the two interannual components in QB-CP El Niño, both the QB and the LF components in the LF-EP El Niño have high amplitudes and their positive peaks almost coincide with the observed El Niño peak, which is responsible for the extremely strong intensity of LF-EP El Niño. The most powerful El Niño events in history $(1972 / 73,1982 / 83,1997 / 98,2015 / 16)$ were all the LF-EP type. During the mature stage of the LF-EP El Niño, the LF component becomes stronger, and the positive SSTAs are centered east of $135^{\circ} \mathrm{W}$. The LF-mixing El Niño event is also dominated by the LF component but has an extremely short or extremely long duration with ambiguous spatial features. The LF component in the LF-mixing El Niño is strong, but the QB component becomes weak. Compared with the QB-CP and LF-EP El Niño, the LF-mixing El Niño has double or triple peaks in the positive phase of its LF component, which is affected by QB or higher-frequency variabilities. The 

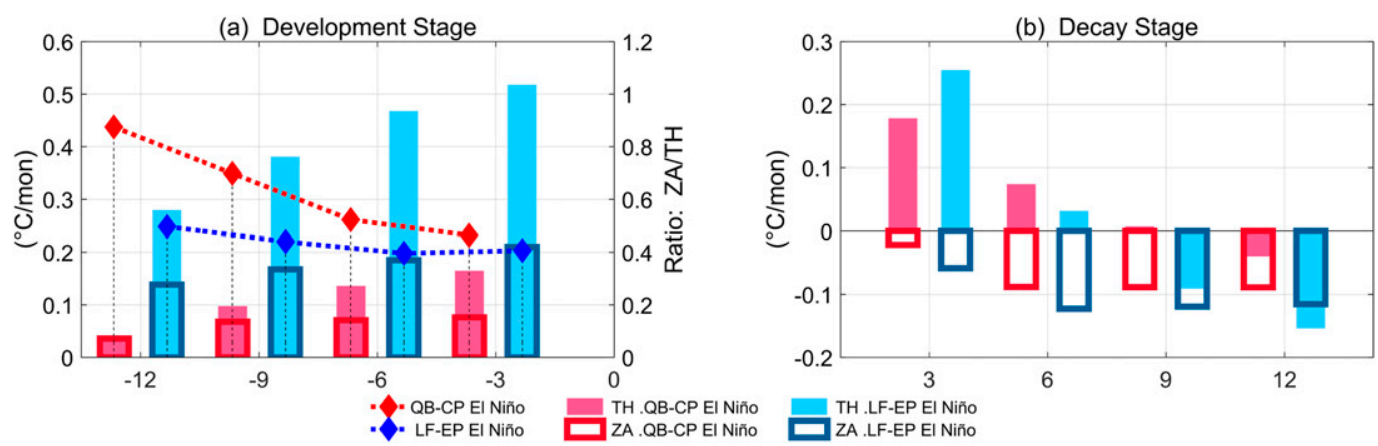

FIG. 11. (a) The TH and ZA terms time-averaged from the start lead month $(x=-12,-9,-6,-3)$ to 1 month before the peak time $(x=-1)$ for the QB-CP El Niño (red bars) and LF-EP El Niño (blue bars). The dashed lines with diamond markers represent the ratios of the time-averaged ZA and TH terms. (b) The TH and ZA terms time-averaged from the peak time $(x=0)$ to the termination time $(x=3,6,9,12)$ for the QB-CP El Niño (red bars) and LF-EP El Niño (blue bars). The TH and ZA terms are area-averaged over $5^{\circ} \mathrm{N}-5^{\circ} \mathrm{S}, 180^{\circ}-90^{\circ} \mathrm{W}$.

LF-mixing La Niña has features similar to those of the LF-mixing El Niño.

The spatial characteristics of La Niña events have similar connections with the QB and LF components compared to El Niño events. The amplitude and phase of the QB-CP La Niña, including the QB and LF components, are nearly symmetrical to those of the QB-CP El Niño. The QB-CP La Niña also has a spatial structure similar to that of the QB-CP El Niño. The LF-EP La Niña with weaker strength and longer duration is differentiated in terms of time evolution with the LF-EP El Niño, but it still has a negative SSTA pattern centered near $120^{\circ} \mathrm{W}$. Meanwhile, the LF-EP La Niña has a strong LF component that is comparable to that in the LF-EP El Niño, but its QB component is much weaker and does not peak simultaneously with the LF component. Hence, although not exactly the same as El Niño, there is evidence showing that the QB and LF components in La Niña events are also associated with ENSO spatial structures.

We have shown that the QB and LF components of ENSO events are connected with the CP and EP ENSOlike spatial patterns, respectively, which provide supporting evidence for the existence of the two ENSO modes, the QB mode and LF mode. The QB mode is characterized by the QB period and the CP ENSO-like spatial pattern, and the LF mode is characterized by the LF period and the EP ENSO-like spatial pattern. The spatiotemporal characteristics of the three types of El Niño and La Niña events depend on the relative activities and phase differences of the two ENSO modes. The two ENSO modes with changing intensities coexist in the tropical Pacific, and their combination is the key to understanding the space-time diversity of ENSO.

We further investigated dynamical features and processes in the QB-CP and LF-EP El Niño events. Due to the very limited number of cases during the available data period, La Niña events were not investigated at this time. Compared with the QB-CP El Niño, the LF-EP El Niño has an earlier development of both the positive Taux and D20 anomalies, where such positive Taux anomalies, coupled with SSTA anomalies, are more widely distributed in the western-central tropical Pacific, with a much stronger amplitude, and the corresponding zonal reversal pattern of the D20 anomalies is also steeper. The TH and ZA terms are the two main positive feedback processes in El Niño. The TH term is dominant in the development stage of both types except during their initiation stages and contributes to the phase transition of the LF-EP El Niño, while the ZA term plays a relatively more important role in the QB-CP El Niño than in the LF-EP El Niño, which is consistent with the theoretical results in Bejarano and Jin (2008). In addition, the ZA makes the main contributions to the phase transitions of both types. In this study, we suggested that the QB and LF modes exhibit different importance in terms of contributions to the observed El Niño/La Niña events. Previous studies suggested that the activity or stability of the two ENSO modes is sensitive to changes in the climate mean state in the tropical Pacific (Bejarano and Jin 2008; Xie and Jin 2018). Indeed, the ENSO, as an air-sea coupled system in the tropical Pacific, is significantly affected by external forcings, such as westerly wind bursts, interdecadal modes, and global warming (e.g., Chen et al. 2015; Cai et al. 2018). Therefore, the two ENSO modes we emphasize here may be affected by different external factors, which require further research.

Acknowledgments. This work was jointly supported by the National Key Research and Development Program on Monitoring, Early Warning and Prevention of Major Natural Disaster (2018YFC1506000), and the China National Science Foundation under Grant 41975094. 


\section{REFERENCES}

An, S.-I., and B. Wang, 2000: Interdecadal change of the structure of the ENSO mode and its impact on the ENSO frequency. J. Climate, 13, 2044-2055, https://doi.org/10.1175/1520-0442(2000) 013<2044:ICOTSO > 2.0.CO;2.

- and F.F. Jin, 2001: Collective role of thermocline and zonal advective feedbacks in the ENSO mode. J. Climate, 14, 3421-3432, https:// doi.org/10.1175/1520-0442(2001)014<3421:CROTAZ>2.0.CO;2.

J. Climate, 17, 2399-2412, https://doi.org/10.1175/1520-0442(2004) 017<2399:NAAOE $>2.0 . \mathrm{CO} ; 2$.

,-- , and I.-S. Kang, 1999: The role of zonal advection feedback in phase transition and growth of ENSO in the Cane-Zebiak model. J. Meteor. Soc. Japan, 77, 1151-1160, https://doi.org/10.2151/jmsj1965.77.6_1151.

Arguez, A., and R. S. Vose, 2011: The definition of the standard WMO climate normal: The key to deriving alternative climate normals. Bull. Amer. Meteor. Soc., 92, 699-704, https://doi.org/ 10.1175/2010BAMS2955.1.

Ashok, K., S. K. Behera, S. A. Rao, H. Weng, and T. Yamagata, 2007: El Niño Modoki and its possible teleconnections. J. Geophys. Res., 112, C11007, https://doi.org/10.1029/2006JC003798.

Barnett, T. P., 1991: The interaction of multiple time scales in the tropical climate system. J. Climate, 4, 269-285, https://doi.org/ 10.1175/1520-0442(1991)004<0269:TIOMTS>2.0.CO;2.

Battisti, D. S., and A. C. Hirst, 1989: Interannual variability in a tropical atmosphere-ocean model: Influence of the basic state, ocean geometry and nonlinearity. J. Atmos. Sci., 46, 1687-1712, https:// doi.org/10.1175/1520-0469(1989)046<1687:IVIATA > 2.0.CO;2.

Bejarano, L., and F.-F. Jin, 2008: Coexistence of equatorial coupled modes of ENSO. J. Climate, 21, 3051-3067, https://doi.org/ 10.1175/2007JCLI1679.1.

Bjerknes, J., 1969: Atmospheric teleconnections from the equatorial Pacific. Mon. Wea. Rev., 97, 163-172, https://doi.org/ 10.1175/1520-0493(1969)097<0163:ATFTEP > 2.3.CO;2.

Cai, W., and Coauthors, 2018: Increased variability of eastern Pacific El Niño under greenhouse warming. Nature, 564, 201206, https://doi.org/10.1038/s41586-018-0776-9.

Cane, M. A., M. Münnich, and S. F. Zebiak, 1990: A study of selfexcited oscillations of the tropical ocean-atmosphere system. Part I: Linear analysis. J. Atmos. Sci., 47, 1562-1577, https://doi.org/10.1175/1520-0469(1990)047<1562:ASOSEO> 2.0.CO;2.

Capotondi, A., and Coauthors, 2015: Understanding ENSO diversity. Bull. Amer. Meteor. Soc., 96, 921-938, https://doi.org/ 10.1175/BAMS-D-13-00117.1.

Chang, P., and Coauthors, 2006: Climate fluctuations of tropical coupled system-The role of ocean dynamics. J. Climate, 19, 5122-5174, https://doi.org/10.1175/JCLI3903.1.

Chen, D., and Coauthors, 2015: Strong influence of westerly wind bursts on El Niño diversity. Nat. Geosci., 8, 339-345, https:// doi.org/10.1038/ngeo2399.

Fu, C., H. Diaz, and J. Fletcher, 1986: Characteristics of the response of sea surface temperature in the central Pacific associated with warm episodes of the Southern Oscillation. Mon. Wea. Rev., 114, 1716-1739, https://doi.org/10.1175/1520-0493(1986)114<1716: COTROS $>2.0 . \mathrm{CO} ; 2$.

Giese, B. S., and S. Ray, 2011: El Niño variability in simple ocean data assimilation (SODA), 1871-2008. J. Geophys. Res., 116, C02024, https://doi.org/10.1029/2010JC006695.

Horii, T., I. Ueki, and K. Hanawa, 2012: Breakdown of ENSO predictors in the 2000s: Decadal changes of recharge/discharge-SST phase relation and atmospheric intraseasonal forcing. Geophys. Res. Lett., 39, L10707, https://doi.org/10.1029/2012GL051740.

$\mathrm{Hu}, \mathrm{S}$., and A. V. Fedorov, 2018: Cross-equatorial winds control El Niño diversity and change. Nat. Climate Change, 8, 798-802, https://doi.org/10.1038/s41558-018-0248-0.

Hu, Z.-Z., A. Kumar, H.-L. Ren, H. Wang, M. L'Heureux, and F.-F. Jin, 2013: Weakened interannual variability in the tropical Pacific Ocean since 2000. J. Climate, 26, 2601-2613, https:// doi.org/10.1175/JCLI-D-12-00265.1.

_ _ - B. Huang, J. Zhu, R.-H. Zhang, and F.-F. Jin, 2017a: Asymmetric evolution of El Niño and La Niña: The recharge/ discharge processes and role of the off-equatorial sea surface height anomaly. Climate Dyn., 49, 2737-2748, https://doi.org/ 10.1007/s00382-016-3498-4.

,,,,---- , and H.-L. Ren, 2017b: Interdecadal variations of ENSO around 1999/2000. J. Meteor. Res., 31, 73-81, https://doi.org/10.1007/s13351-017-6074-x.

Huang, B., and Coauthors, 2017: Extended Reconstructed Sea Surface Temperature, version 5 (ERSSTv5): Upgrades, validations, and intercomparisons. J. Climate, 30, 8179-8205, https://doi.org/10.1175/JCLI-D-16-0836.1.

Huang, N. E., and Coauthors, 1998: The empirical mode decomposition and the Hilbert spectrum for nonlinear and nonstationary time series analysis. Proc. Roy. Soc. London, A454, 903-995, https://doi.org/10.1098/rspa.1998.0193.

Jiang, N., J. D. Neelin, and M. Ghil, 1995: Quasi-quadrennial and quasi-biennial variability in the equatorial Pacific. Climate Dyn., 12, 101-112, https://doi.org/10.1007/BF00223723.

Jin, F.-F., 1996: Tropical ocean-atmosphere interaction, the Pacific cold tongue, and the El Niño-Southern Oscillation. Science, 274, 76-78, https://doi.org/10.1126/science.274.5284.76.

_ 1997a: An equatorial ocean recharge paradigm for ENSO. Part I: Conceptual model. J. Atmos. Sci., 54, 811-829, https://doi.org/ 10.1175/1520-0469(1997)054<0811:AEORPF > 2.0.CO;2. , 1997b: An equatorial ocean recharge paradigm for ENSO. Part II: A stripped-down coupled model. J. Atmos. Sci., 54, 830-847, https:// doi.org/10.1175/1520-0469(1997)054<0830:AEORPF>2.0.CO;2. , and S.-I. An, 1999: Thermocline and zonal advective feedbacks within the equatorial ocean recharge oscillator model for ENSO. Geophys. Res. Lett., 26, 2989-2992, https://doi.org/ 10.1029/1999GL002297.

- — - A. Timmermann, and J. Zhao, 2003: Strong El Niño events and nonlinear dynamical heating. Geophys. Res. Lett., 30, 1120, https://doi.org/10.1029/2002GL016356.

, S. T. Kim, and L. Bejarano, 2006: A coupled-stability index for ENSO. Geophys. Res. Lett., 33, L23708, https://doi.org/ 10.1029/2006GL027221.

Kao, H.-Y., and J.-Y. Yu, 2009: Contrasting eastern-Pacific and central-Pacific types of ENSO. J. Climate, 22, 615-632, https:// doi.org/10.1175/2008JCLI2309.1.

Kessler, W. S., 2002: Is ENSO a cycle or a series of events? Geophys. Res. Lett., 29, 2125, https://doi.org/10.1029/2002GL015924.

Kug, J.-S., and Y.-G. Ham, 2011: Are there two types of La Niña? Geophys. Res. Lett., 38, L16704, https://doi.org/10.1029/2011GL048237.

, F.-F. Jin, and S.-I. An, 2009: Two types of El Niño events: Cold tongue El Niño and warm pool El Niño. J. Climate, 22, 1499-1515, https://doi.org/10.1175/2008JCLI2624.1.

Kumar, A., and Z.-Z. Hu, 2014: Interannual and interdecadal variability of ocean temperature along the equatorial Pacific in conjunction with ENSO. Climate Dyn., 42, 1243-1258, https:// doi.org/10.1007/s00382-013-1721-0.

Larkin, N. K., and D. E. Harrison, 2002: ENSO warm (El Niño) and cold (La Niña) event life cycles: Ocean surface anomaly patterns, their 
symmetries, asymmetries, and implications. J. Climate, 15, 1118-1140, https://doi.org/10.1175/1520-0442(2002)015<1118: EWENOA $>2.0 . \mathrm{CO} ; 2$.

$\longrightarrow$, and - 2005a: On the definition of El Niño and associated seasonal average U.S. weather anomalies. Geophys. Res. Lett., 32, L13705, https://doi.org/10.1029/2005GL022738.

$\longrightarrow$, and $\longrightarrow, 2005 \mathrm{~b}$ : Global seasonal temperature and precipitation anomalies during El Niño autumn and winter. Geophys. Res. Lett., 32, L16705, https://doi.org/10.1029/2005GL022860.

Lemmon, D. E., and K. B. Karnauskas, 2019: A metric for quantifying El Niño pattern diversity with implications for ENSOmean state interaction. Climate Dyn., 52, 7511-7523, https:// doi.org/10.1007/s00382-018-4194-3.

Lu, B., F.-F. Jin, and H.-L. Ren, 2018: A coupled dynamic index for ENSO periodicity. J. Climate, 31, 2361-2376, https://doi.org/ 10.1175/JCLI-D-17-0466.1.

McPhaden, M. J., 2012: A 21st century shift in the relationship between ENSO SST and warm water volume anomalies. Geophys. Res. Lett., 39, L09706, https://doi.org/10.1029/2012GL051826.

Neelin, J. D., D. S. Battisti, A. C. Hirst, F.-F. Jin, Y. Wakata, T. Yamagata, and S. E. Zebiak, 1998: ENSO theory. J. Geophys. Res., 103, 14261-14 290, https://doi.org/10.1029/97JC03424.

Okumura, Y. M., and C. Deser, 2010: Asymmetry in the duration of El Niño and La Niña. J. Climate, 23, 5826-5843, https://doi.org/ 10.1175/2010JCLI3592.1.

_- M. Ohba, C. Deser, and H. Ueda, 2011: A proposed mechanism for the asymmetric duration of El Niño and La Niña. J. Climate, 24, 3822-3829, https://doi.org/10.1175/2011JCLI3999.1.

Philander, S. G. H., 1983: El Niño Southern Oscillation phenomena. Nature, 302, 295-301, https://doi.org/10.1038/302295a0.

Picaut, J., F. Masia, and Y. du Penhoat, 1997: An advective-reflective conceptual model for the oscillatory nature of the ENSO. Science, 277, 663-666, https://doi.org/10.1126/science.277.5326.663.

Qian, C., Z. Wu, C. Fu, and D. Wang, 2011: On changing El Niño: A view from time-varying annual cycle, interannual variability, and mean state. J. Climate, 24, 6486-6500, https://doi.org/ 10.1175/JCLI-D-10-05012.1.

Rasmusson, E. M., and T. H. Carpenter, 1982: Variations in tropical sea surface temperature and surface wind fields associated with the Southern Oscillation/El Niño. Mon. Wea. Rev., 110, 354-384, https:// doi.org/10.1175/1520-0493(1982)110<0354:VITSST>2.0.CO;2.

— X. Wang, and C. F. Ropelewski, 1990: The biennial component of ENSO variability. J. Mar. Syst., 1, 71-96, https:// doi.org/10.1016/0924-7963(90)90153-2.

Ren, H.-L., and F.-F. Jin, 2011: Niño indices for two types of ENSO. Geophys. Res. Lett., 38, L04704, https://doi.org/ 10.1029/2010GL046031.

—, and - 2013: Recharge oscillator mechanisms in two types of ENSO. J. Climate, 26, 6506-6523, https://doi.org/10.1175/ JCLI-D-12-00601.1.

, - M. M. Stuecker, and R. Xie, 2013: ENSO regime change since the late 1970s as manifested by two types of ENSO. J. Meteor. Soc. Japan, 91, 835-842, https://doi.org/10.2151/jmsj.2013-608.

—, F. F. Jin, B. Tian, and A. A. Scaife, 2016: Distinct persistence barriers in two types of ENSO. Geophys. Res. Lett., 43, 10973 10 979, https://doi.org/10.1002/2016GL071015.

—, B. Lu, J. Wan, B. Tian, and P. Zhang, 2018: Identification standard for ENSO events and its application to climate monitoring and prediction. J. Meteor. Res., 32, 923-936, https://doi.org/10.1007/s13351-018-8078-6.

, and Coauthors, 2019a: Seasonal predictability of winter ENSO types in operational dynamical model predictions. Climate Dyn., 52, 3869-3890, https://doi.org/10.1007/s00382-018-4366-1.
_ J. Zuo, and Y. Deng, 2019b: Statistical predictability of Niño indices for two types of ENSO. Climate Dyn., 52, 5361-5382, https://doi.org/10.1007/s00382-018-4453-3.

Ropelewski, C. F., M. S. Halpert, and X. Wang, 1992: Observed tropospheric biennial variability and its relationship to the Southern Oscillation. J. Climate, 5, 594-614, https://doi.org/ 10.1175/1520-0442(1992)005<0594:OTBVAI >2.0.CO;2.

Stevenson, S., A. Capotondi, J. Fasullo, and B. Otto-Bliesner, 2019: Forced changes to twentieth century ENSO diversity in a last millennium context. Climate Dyn., 52, 7359-7374, https:// doi.org/10.1007/s00382-017-3573-5.

Suarez, M. J., and P. S. Schopf, 1988: A delayed action oscillator for ENSO. J. Atmos. Sci., 45, 3283-3287, https://doi.org/10.1175/ 1520-0469(1988)045<3283:ADAOFE $>2.0 . C O ; 2$.

Timmermann, A., and Coauthors, 2018: El Niño-Southern Oscillation complexity. Nature, 559, 535-545, https://doi.org/10.1038/s41586018-0252-6.

Trenberth, K. E., G. W. Branstator, D. Karoly, A. Kumar, N.-C. Lau, and C. Ropelewski, 1998: Progress during TOGA in understanding and modeling global teleconnections associated with tropical sea surface temperatures. J. Geophys. Res., 103, 14 291-14 324, https://doi.org/10.1029/97JC01444.

Vimont, D. J., D. S. Battisti, and A. C. Hirst, 2003: The seasonal footprinting mechanism in the CSIRO general circulation models. J. Climate, 16, 2653-2667, https://doi.org/10.1175/ 1520-0442(2003)016<2653:TSFMIT >2.0.CO;2.

Wallace, J. M., E. M. Rasmusson, T. P. Mitchell, V. E. Kousky, E. S. Sarachik, and H. von Storch, 1998: On the structure and evolution of ENSO-related climate variability in the tropical Pacific: Lessons from TOGA. J. Geophys. Res., 103, 1424114 259, https://doi.org/10.1029/97JC02905.

Wang, C., and J. Picaut, 2004: Understanding ENSO physics-A review. Earth Climate: The Ocean-Atmosphere Interaction, Geophys. Monogr., Vol. 147, Amer. Geophys. Union, 21-48.

Wang, L., J.-Y. Yu, and H. Paek, 2017: Enhanced biennial variability in the Pacific due to Atlantic capacitor effect. Nat. Commun., 8, 14887, https://doi.org/10.1038/ncomms14887.

Wang, R., and H.-L. Ren, 2017: The linkage between two ENSO types/modes and the interdecadal changes of ENSO around the year 2000. Atmos. Ocean. Sci. Lett., 10, 168-174, https:// doi.org/10.1080/16742834.2016.1258952.

Weisberg, R. H., and C. Z. Wang, 1997: A western Pacific oscillator paradigm for the El Niño-Southern Oscillation. Geophys. Res. Lett., 24, 779-782, https://doi.org/10.1029/97GL00689.

Weng, H., K. Ashok, S. K. Behera, S. A. Rao, and T. Yamagata, 2007: Impacts of recent El Niño Modoki on dry/wet conditions in the Pacific rim during boreal summer. Climate Dyn., 29, 113-129, https://doi.org/10.1007/s00382-007-0234-0.

White, B. W., Y. M. Tourre, M. Barlow, and M. Dettinger, 2003: A delayed action oscillator shared by biennial, interannual, and decadal signals in the Pacific basin. J. Geophys. Res., 108, 3070 , https://doi.org/10.1029/2002JC001490.

WMO, 1989: Calculation of monthly and annual 30-year standard normals. WMO/TD-341, WCDP-10, World Meteorological Organization, 13 pp., http://www.posmet.ufv.br/wp-content/ uploads/2016/09/MET-481-WMO-341.pdf.

_ 2007: The role of climatological normals in a changing climate. WMO/TD-1377, WCDMP-61, World Meteorological Organization, 130 pp., https://library.wmo.int/index.php? $\mathrm{lvl}=$ notice_display\&id $=16659$.

Wu, Z., and N. E. Huang, 2009: Ensemble empirical mode decomposition: A noise-assisted data analysis method. Adv. Adapt. Data Anal., 1 (1), 1-41, https://doi.org/10.1142/S1793536909000047. 
Xiang, B. Q., B. Wang, and T. Li, 2013: A new paradigm for the predominance of standing central Pacific warming after the late 1990s. Climate Dyn., 41, 327-340, https://doi.org/10.1007/ s00382-012-1427-8.

Xie, R., and F.-F. Jin, 2018: Two leading ENSO modes and El Niño types in the Zebiak-Cane model. J. Climate, 31, 1943-1962, https://doi.org/10.1175/JCLI-D-17-0469.1.

_ , F. Huang, F.-F. Jin, and J. Huang, 2015: The impact of basic state on quasi-biennial periodicity of central Pacific ENSO over the past decade. Theor. Appl. Climatol., 120, 55-67, https://doi.org/10.1007/s00704-014-1150-y.

Yeh, S.-W., J.-S. Kug, B. Dewitte, M.-H. Kwon, B. P. Kirtman, and F.-F. Jin, 2009: El Niño in a changing climate. Nature, 461, 511-514, https://doi.org/10.1038/nature08316.

, and S.-I. An, 2014: Recent progresses on two types of El Niño: Observations, dynamics, and future changes. Asia-Pac. J. Atmos. Sci., 50, 69-81, https://doi.org/10.1007/s13143-0140028-3.

Yeo, S.-R., and K.-Y. Kim, 2014: Global warming, low-frequency variability, and biennial oscillation: An attempt to understand the physical mechanisms driving major ENSO events. Climate Dyn., 43, 771-786, https://doi.org/10.1007/S00382-013-1862-1.

- S.-W. Yeh, K.-Y. Kim, and W. Kim, 2017: The role of lowfrequency variation in the manifestation of warming trend and
ENSO amplitude. Climate Dyn., 49, 1197-1213, https:// doi.org/10.1007/s00382-016-3376-0.

Yu, J.-Y., and S. T. Kim, 2010: Three evolution patterns of CentralPacific El Niño. Geophys. Res. Lett., 37, L08706, https:// doi.org/10.1029/2010GL042810.

- and _ 2013: Identifying the types of major El Niño events since 1870. Int. J. Climatol., 33, 2105-2112, https://doi.org/ 10.1002/joc.3575.

Zebiak, S. E., and M. A. Cane, 1987: A model El Niño-Southern Oscillation. Mon. Wea. Rev., 115, 2262-2278, https://doi.org/ 10.1175/1520-0493(1987)115<2262:AMENO>2.0.CO;2.

Zhang, S., M. J. Harrison, A. Rosati, and A. T. Wittenberg, 2007: System design and evaluation of coupled ensemble data assimilation for global oceanic climate studies. Mon. Wea. Rev., 135, 3541-3564, https://doi.org/10.1175/MWR3466.1.

Zhang, W., F.-F. Jin, J. Li, and H.-L. Ren, 2011: Contrasting impacts of two-type El Niño over the western North Pacific during boreal autumn. J. Meteor. Soc. Japan, 89, 563-569, https://doi.org/10.2151/jmsj.2011-510.

- - - H.-L. Ren, J. Li, and J.-X. Zhao, 2012: Differences in teleconnection over the North Pacific and rainfall shift over the USA associated with two types of El Niño during boreal autumn. J. Meteor. Soc. Japan, 90, 535-552, https://doi.org/ 10.2151/jmsj.2012-407. 